\title{
Objective Evaluation of Satellite Precipitation Datasets for Heavy Precipitation Events Caused by Typhoons in the Philippines
}

\section{Putu Aryastana}

National Central University

Chian-Yi Liu ( $\square$ cyliu7@gate.sinica.edu.tw )

Academia Sinica https://orcid.org/0000-0003-1725-4405

Ben Jong-Dao Jou

National Taiwan University

Esperanza Cayanan

Philippine Atmospheric, Geophysical and Astronomical Services Administration

Jason Pajimola Punay

National Central University

Research article

Keywords: GSMaP, heavy precipitation, IMERG, PERSIANN, Philippines, typhoon

Posted Date: July 14th, 2021

DOI: https://doi.org/10.21203/rs.3.rs-684518/v1

License: (c) (1) This work is licensed under a Creative Commons Attribution 4.0 International License.

Read Full License 


\section{Objective evaluation of satellite precipitation datasets for heavy precipitation events caused by typhoons in the Philippines}

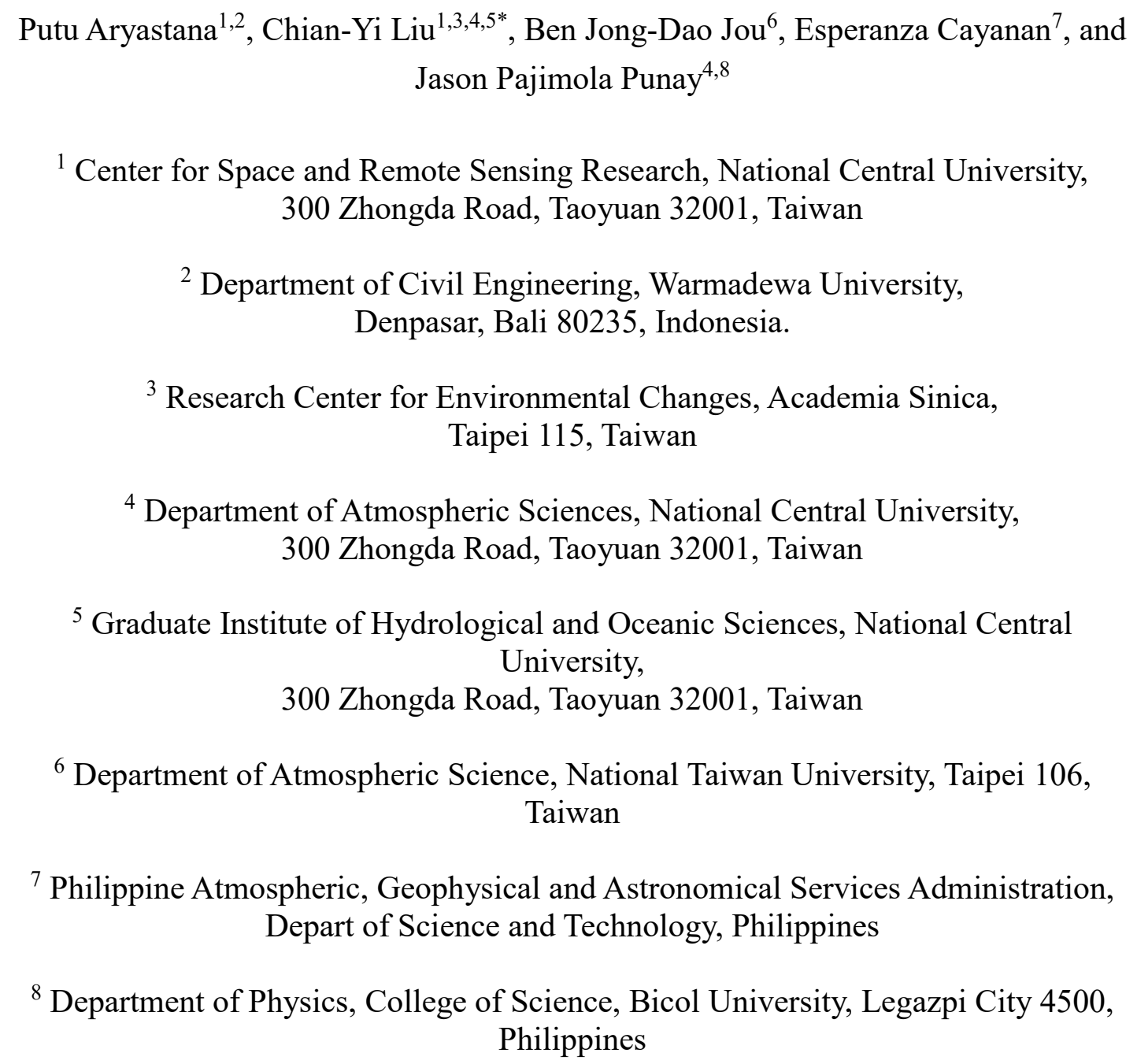

3 July 2021 


\section{Key Points/Highlights:}

48 1. Satellite precipitation datasets during five typhoon-related heavy precipitation

49 events in the Philippines were evaluated for the first time.

50 2. The 34-knot wind radii of the typhoons were used to select rain gauge

51 measurements.

52 3. The satellite precipitation datasets were analyzed in terms of various rainfall intensities, the terrain, and wind velocity effects.

56 Running title: Satellite precipitation datasets for heavy precipitation events caused by

57 typhoons in the Philippines 
Extreme weather events, such as typhoons, have occurred more frequently in the

62 last few decades in the Philippines. The heavy precipitation caused by typhoons is

63 difficult to measure with traditional instruments, such as rain gauges and ground-based

64 radar, because these instruments have an uneven distribution in remote areas. Satellite

65 precipitation datasets (SPDs) provide integrated spatial coverage of rainfall 66 measurements, even for remote areas. This study performed subdaily (3-hour)

67 assessments of SPDs (i.e., the Integrated Multi-satellitE Retrievals for Global 68 Precipitation Measurement [IMERG], Global Satellite Mapping of Precipitation 69 [GSMaP], and Precipitation Estimation from Remotely Sensed Information Using 70 Artificial Neural Networks datasets) during five typhoon-related heavy precipitation 71 events in the Philippines between 2016 and 2018. The aforementioned assessments 72 were performed through a point-to-grid comparison by using continuous and 73 volumetric statistical validation indices for the 34-knot wind radii of the typhoons,

74 rainfall intensity, the terrain, and wind velocity effects. The results revealed that the

75 IMERG exhibited good agreement with rain gauge measurements and exhibited high

76 performance in detecting rainfall during five typhoon events, whereas the GSMaP

77 exhibited high agreement during peak rainfall. All the SPDs tended to overestimate 78 rainfall during light to moderate rainfall events and underestimate rainfall during heavy 
79 to extreme events. The IMERG exhibited a strong ability to detect moderate rainfall

80 events (5-15 mm/3 hours), whereas the GSMaP exhibited superior performance in

81 detecting heavy to extreme rainfall events $(15-25,25-50$, and $>50 \mathrm{~mm} / 3$ hours $)$. The

82 GSMaP exhibited the best performance for detecting heavy rainfall at high elevations,

83 whereas the IMERG exhibited the best performance for rainfall detection at low

84 elevations. The IMERG exhibited a strong ability to detect heavy rainfall under various

85 wind speeds. A strong ability to detect heavy rainfall events for different wind speeds

86 in the western and eastern parts of the mountainous region of Luzon were found for the

87 GSMap and IMERG, respectively. This study demonstrated that the IMERG and

88 GSMaP datasets exhibit promising performance in detecting heavy precipitation caused

89 by typhoon events.

90

91

92 Keywords:

93 GSMaP, heavy precipitation, IMERG, PERSIANN, Philippines, typhoon

94

95

96 

the topography (Jones et al. 2003; Wu et al. 2009; Zhang et al. 2010; Yang et al. 2011;

113 Yu and Cheng 2013; Huang and Lin 2014; Chen and Wu 2016; Cheung et al. 2018; 114 Hon, 2020). Because the diameters of typhoons range from 100 to $2000 \mathrm{~km}$, monitoring 115 the heavy rainfall caused by typhoons with conventional instruments is difficult (Huang

\section{Introduction}

a certain threshold; tends to be of short duration; can threaten human activity; and often

causes natural disasters (such as floods and landslides) that result in social problems,

environmental damage, and material losses (Bell et al. 2004; Hong et al. 2006; Wu et

al. 2012; Stampoulis et al. 2013; Chen and Wu 2016). Heavy precipitation can be triggered by events such as tropical cyclones (typhoons) (Wang et al. 2016). Typhoons can cause heavy precipitation from the eye to the eyewall of the storm, a distance that can be tends to hundreds of kilometers across (Lonfat et al. 2007; Kimball 2008;

Yokoyama and Takayabu 2008; Wang et al. 2009). Typhoons can also cause heavy rainfall in distant regions located thousands of kilometers from the center of a typhoon

(Ross and Kurihara 1995; Wang et al. 2009; Chen and Wu 2016). The quantity of rainfall caused by typhoons is affected by several factors, such as the internal typhoon structure, track variations, large-scale moisture convergence, convection strength, cloud microphysics, typhoon interaction at midlatitude, and typhoon interaction with the heavy rainfall caused by typhoons with conventional instruments is difficult (Huang 
et al. 2019). Therefore, achieving an accurate quantitative estimation of heavy rainfall

117 caused by typhoon events represents the largest challenge in hydrometeorological

118 research and natural disaster modeling.

119 The analysis of heavy precipitation requires an accurate precipitation dataset with

120 global coverage as well as high spatial and temporal resolutions (Setiawati et al. 2016;

121 Liu et al. 2019; Liu et al. 2020a). Accurate rainfall data with high spatial and temporal

122 resolution at regional and global scales are difficult to access in the fields of hydrology

123 and weather forecasting. In situ measurements from rain gauge stations can supply

124 reliable point-scale rainfall data (Duan et al. 2016). However, rain gauge stations are

125 unevenly distributed, with few such stations being found in remote and mountainous

126 areas, which limits the quantity of accurate spatial and temporal data that can be

127 obtained for these areas (Javanmard et al. 2010; Ji et al. 2020). Weather radar can

128 provide local precipitation data with sufficiently high spatial and temporal resolution.

129 However, these data are affected by deviations from electromagnetic signals due to the

130 effect of the terrain in mountainous areas ( $\mathrm{Li}$ et al. 2013).

131 The rapid development of remote sensing techniques in the fields of hydrology

132 and meteorology has resulted in the development of several satellite-based precipitation

133 estimation methods with global coverage as well as high spatial and temporal resolution

134 (Wu et al. 2019; Nashwan et al. 2020). Satellite precipitation datasets (SPDs) released 
135 online to the public can overcome the problem caused by the unavailability of rain

136 gauge station and weather radar data. Rainfall estimation techniques using SPDs are

137 broadly based on the thermal infrared (TIR) radiation of geostationary satellites, the

138 passive microwave (PMW) radiations recorded by sensors in low Earth orbiting

139 satellites, or a combination of TIR and PMW radiations (Duan et al. 2016; Liu et al.

140 2019; Levizzani and Cattani 2019). These estimation techniques are not perfect in terms

141 of accurately predicting rainfall intensity. Therefore, calibration and validation are

142 necessary before SPDs can be used for hydrological modeling or meteorological

143 disaster observation. Global coverage can be achieved by several SPDs, such as the

144 Precipitation Estimation from Remotely Sensed Information Using Artificial Neural

145 Networks (PERSIANN; Hsu et al. 1997), the Climate Prediction Center Merged

146 Analysis of Precipitation (Xie and Arkin 1997), the Climate Prediction Center

147 Morphing Algorithm (CMORPH; Joyce et al. 2004), the Global Satellite Mapping of

148 Precipitation (GSMaP; Okamoto et al. 2005), the Integrated Multi-satellitE Retrievals

149 for Global Precipitation Measurement (IMERG; Hou et al. 2014), the Climate Hazards

150 Group InfraRed Precipitation with Station (CHIRPS; Funk et al. 2015), and the

151 Multisource Weighted-Ensemble Precipitation (Beck et al. 2017) datasets.

152 Revisions in the algorithms of SPDs had been made based on key studies which

153 improved the capability of SPDs in detecting heavy rainfall. Studies have evaluated the 
154 performance of the Tropical Rainfall Measuring Mission (TRMM) 3B42 dataset during

155 an extreme rainfall event (Pombo and de Oliveira 2015; Parida et al. 2017; Huang et al.

156 2018; Rashid et al. 2018; Liu et al. 2019; Palharini et al. 2020). Pombo and de Oliveira

157 (2015) evaluated the performance of the TRMM 3B42 dataset in estimating the annual

158 maximum daily rainfall in Angola. They discovered that the TRMM 3B42 dataset

159 showed promise for the estimation of heavy precipitation events. The TRMM 3B42

160 dataset provided underestimated values compared with the rain gauge measurements.

161 In a previous study, compared with rain gauge measurements for heavy precipitation

162 events during June 2013 in the Western Himalayas, the TRMM 3B42 and CMORPH

163 datasets underestimated the daily rainfall and peak rainfall intensity, whereas the

164 GSMaP dataset both overestimated and underestimated rainfall values (Parida et al.

165 2017). The TRMM 3B42 dataset exhibited a promising ability to determine the monthly

166 maximum 1-day precipitation, monthly maximum 2-day consecutive precipitation,

167 monthly maximum 5-day consecutive precipitation, and total annual precipitation for

168 wet days in China between 2009 and 2013 (Huang et al. 2018). For flooding caused by

169 heavy rainfall from September 1 to September 7, 2014, in the Kashmir Valley in India,

170 the TRMM 3B42 and GSMaP datasets underestimated rainfall, whereas the IMERG

171 dataset demonstrated superior performance to that of the rain gauges in terms of daily

172 estimation, with high correlation and Nash-Sutcliffe coefficients and the lowest bias 
173 value (Rashid et al. 2018). TRMM 3B42 version 7 outperformed the PERSIANN and

174 CMORPH datasets in terms of accuracy of detecting monthly and annual heavy

175 precipitation events from 2009 to 2014 in the Wei River Basin in China (Liu et al. 2019).

176 The calibrated rain gauge of the TRMM, GSMaP, CMORPH, CHIRPS, and

177 PERSIANN datasets outperformed compare to the near-real-time of each datasets in

178 terms of estimating heavy rainfall in South America from 2012 to 2016 (Palharini et al.

179 2020). The accuracy of the CMORPH dataset was higher than that of the PERSIANN

180 dataset in terms of radar precipitation observations of heavy rainfall during seven major

181 flood events in regions of various terrains in northern Italy and southern France between

1822003 and 2008 (Stampoulis et al. 2013). The GSMaP near-real-time dataset calibrated

183 by gauges outperformed the uncalibrated dataset in terms of estimating daily and

184 weekly heavy precipitation in East Asia and the Western Pacific from April 2000 to

185 March 2019 (Tashima et al. 2020). Studies have investigated the ability of SPDs to

186 measure heavy precipitation events on daily, monthly, seasonal, and annual scales.

187 Therefore, the ability of SPDs to measure heavy participation on a subdaily (3-hour)

188 scale must be investigated.

189 Several studies have compared the abilities of SPDs and rain gauges to measure

190 typhoon-related heavy precipitation events. Yu et al. (2009) performed 6-hourly and

191 daily evaluations of TRMM 3B42 version 6, the CMORPH dataset, and the 
192 Geostationary Meteorological Satellite-5 infrared brightness temperature dataset in

193 mainland China by using descriptive and categorical statistics. Chen et al. (2013)

194 validated the TRMM, PERSIANN, and CMORPH datasets at various spatial and

195 temporal resolutions for the extreme 2009 Typhoon Morakot in Taiwan by using

196 descriptive and categorical statistics. Wang et al. (2016) evaluated the integrated

197 rainfall data derived from the Climate Prediction Center morphing technique and gauge

198 observations in terms of the estimation of heavy precipitation related to seven typhoon

199 events by using rain gauge stations in areas within $400 \mathrm{~km}$ of the typhoon center. Huang

200 et al. (2019) investigated the accuracy of the IMERG Early and Final Run datasets in

201 terms of the probability distribution of precipitation rates, spatiotemporal variability,

202 bias analysis, and contingency scores to detect heavy rainfall caused by six typhoons in

203 the coastal area of the Pearl River Delta in southern China. Pham and Vu (2020)

204 examined the horizontal and vertical precipitation structures of typhoons in the central

205 coastal areas of Vietnam by using the TRMM and GSMaP datasets. Various studies

206 that have compared the abilities of SPDs to detect heavy rainfall caused by landfalling

207 typhoons have suggested performing a comparison in terms of rainfall distribution and

208 spatiotemporal scale, analyzing rain gauges in areas within $400 \mathrm{~km}$ of the center of a

209 typhoon in coastal regions, and using descriptive and categorical statistics to perform 
an analysis. Therefore, the effects of terrain and wind velocity on the ability of SPDs to

211 detect heavy precipitation caused by typhoons must be investigated.

The Philippines is an archipelago with more than 7100 islands of complex

213 topography (Ramos et al. 2016; Bagtasa 2017). Two of its islands, namely Luzon in the

214 north and Mindanao in the south, have long chains of mountains, whereas the Visayas

215 region, which is located in the center of the country, consists of small islands (Ramos

216 et al. 2016; Bagtasa 2017). The Philippines frequently experiences typhoons that form

217 in the Northwestern Pacific Basin (Weinkle et al. 2012; Bagtasa, 2017). Every year,

218 approximately 19 typhoons cross the border of the Philippines, and half of these

219 typhoons make landfall (Cinco et al. 2016; Bagtasa 2017). Few studies have evaluated

220 the performance of SPDs for predicting precipitation in the Philippines. Jamandre and

221 Narisma (2013) investigated the error characteristics of the TRMM and CMORPH

222 datasets against the data of ground stations and the Asian Precipitation Highly-Resolved

223 Observational Data Integration Towards the Evaluation of Water Resources

224 (APHRODITE) gridded precipitation dataset from 2003 to 2005. Ramos et al. (2016)

225 evaluated the performance of the TRMM, CMORPH, GSMaP, and PERSIANN

226 datasets and compared their performance with that of measurements from 52 rain gauge

227 stations between 1998 and 2015. However, to the best of our knowledge, no study has

228 assessed the performance of SPDs during heavy precipitation events caused by 
229 typhoons in the Philippines. Therefore, this study evaluated the performance of three

230 SPDs, namely the IMERG, GSMaP, and PERSIANN datasets, during five typhoon-

231 related heavy precipitation events in the Philippines between 2016 and 2018. The

232 current study evaluated the performance of the aforementioned SPDs by comparing

233 their data with those of ground rain gauges in terms of the 34-knot wind radius (R34)

234 of a typhoon, rainfall intensity, and the effects of terrain and wind velocity. Section 2

235 describes the study area. Section 3 provides a detailed description of the dataset and

236 methodology used in this study. Section 4 describes the performance of the three SPDs

237 in terms of rainfall intensity, terrain, and wind velocity effects. Finally, Section 5

238 summarizes our findings.

\section{$240 \quad 2$ Study Area}

241 The study area was the Philippines, which is located between $4^{\circ} 40^{\prime} \mathrm{N}$ and $21^{\circ} 10^{\prime} \mathrm{N}$

242 and between $116^{\circ} 40^{\prime} \mathrm{E}$ and $126^{\circ} 34^{\prime} \mathrm{E}$. This country has a total area of $300,055 \mathrm{~km}^{2}$

243 (Figure 1a). The Philippines is located off the southeast coast of continental Asia across

244 the South China Sea in the strategic zone between China, Taiwan, Borneo, and

245 Indonesia. The Philippines is surrounded by the sea and is the only Southeast Asian

246 country to not border neighboring countries (Bautista 2011). This country has a tropical

247 maritime climate, and its seasonal changes are influenced by northeast and southwest 
monsoon activity (Cinco et al. 2016). The Philippines experiences a cool dry season

249 from December to February, a hot dry season from March to May, and a rainy season

250 from June to November (The Philippine Atmospheric, Geophysical and Astronomical

251 Services Administration [PAGASA]). Precipitation is the essential climatic factor of

252 the Philippines. The distribution of precipitation in the country differs from one region

253 to another and depends on the direction of moisture-bearing winds and the location of

254 mountain systems (PAGASA). The mean annual precipitation of the Philippines ranges

255 between 965 and $4064 \mathrm{~mm}$ per year (PAGASA). Precipitation in many areas of the

256 Philippines is also influenced by typhoons (Ramos et al. 2016). Particular areas in the

257 northern Philippines can receive approximately 50\% to $60 \%$ of their annual

258 precipitation from passing typhoons (Kubota and Wang 2009).

2603 Datasets and Methods

\section{$261 \quad 3.1$ Datasets}

The multisource datasets used in this study can be categorized into four types:

typhoon event data; traditional observational rainfall data obtained from surface rain

264 gauges; precipitation information estimated from satellite measurements; and wind

265 vector data, which constitute a reanalysis dataset. The following subsections provide a

266 brief description of these four types of data. 


\subsubsection{Typhoon Events}

Table 1 presents brief descriptions of five typhoon events that passed over the

269 Philippines. The information regarding the typhoons was provided by the International

270 Best Track Archive for Climate Stewardship (IBTrACS). IBTrACS maintains an

271 archive of the typhoon best track data for specific locations to add to the knowledge on

272 the distribution, frequency, and intensity of typhoons worldwide. The World

273 Meteorological Organization Tropical Cyclone Programme has endorsed IBTrACS as

274 an official recording and distribution resource for typhoon best track data (Knapp et al.

275 2010). The typhoon best track data contain 3-hour and long-term typhoon positioning

276 records (from 1980 to the present). The typhoon track data are available online at

277 https://climatedataguide.ucar.edu/climate-data/ibtracs-tropical-cyclone-best-track-data.

278 The five typhoons analyzed in this study passed over Luzon island. Typhoons

279 Mangkhut and Haima passed through the north, Typhoon Sarika passed through the

280 middle, and typhoons Nock-ten and Doksuri passed through the south of the Luzon

281 island. The five typhoons were classified into various categories according to

282 PAGASA's tropical cyclone intensity scale, namely typhoons (Mangkhut, Sarika,

283 Haima, and Nock-ten), and tropical storms (Doksuri). 


\subsubsection{Data from Rain Gauge Measurements}

The data from rain gauge measurements were used as a reference to evaluate the

286 performance of the SPDs. Three-hour rainfall observation data for typhoons making

287 landfall in the Philippines were obtained from PAGASA, the Department of Science

288 and Technology, the Republic of the Philippines. PAGASA provides rainfall data from

289222 automatic weather stations distributed across the Philippines. A total of 66 rain

290 gauge stations were selected on the basis of whether the spatial distribution was affected

291 by the R34 values of the typhoons and the completeness of the desired data. Table 1

292 lists the number of selected rain gauge stations within the R34 during the passing of the

293 storm. PAGASA has made available high-quality rain gauge data for the five

294 considered typhoon events.

295 3.1.3 IMERG Dataset

296 The high-resolution IMERG dataset is an improvement on the TRMM

297 Multisatellite Precipitation Analysis dataset, whose global coverage data were made

298 available from June 2000. The IMERG program was initiated by the National

299 Aeronautics and Space Administration (NASA) and the Japan Aerospace Exploration

300 Agency (JAXA). Its algorithm intercalibrates, merges, and interpolates all available

301 satellite microwave precipitation measurements, microwave-calibrated infrared

302 measurements, surface rain gauge analyses, and other possible rainfall estimates on 
303 wide temporal and spatial scales for nearly the entire globe (Huffman et al. 2019). The

304 IMERG dataset provides half-hourly, daily, and monthly rainfall estimation at a spatial

305 resolution of $0.1^{\circ}$. The IMERG dataset contains three types of data in terms of time

306 release, namely early-, late-, and final-run data. The time-release delay is 4 hours for

307 the early-run data, 12 hours for the late-run data, and 3.5 months for the final-run data

308 (Huffman et al. 2019). This study used the latest Level-3 IMERG half-hourly data from

309 version 06B of the final-run dataset. The final-run dataset exhibits superior performance

310 to that of the early- and late-run datasets. The final-run dataset is also more appropriate

311 for use in climate and hydrological studies than the other two datasets are (Tang et al.

312 2016). The IMERG dataset is available online at https://gpm.nasa.gov/data/directory.

\section{3.1.4 GSMaP Dataset}

314 The GSMaP dataset is a satellite-based precipitation dataset constructed by the

315 Core Research for Evolutional Science and Technology program under the authority of

316 the Japan Science and Technology Agency between 2002 and 2007, and the

317 aforementioned program was extended by the JAXA (Ushio et al. 2009; Liu et al.

318 2020a). The GSMaP algorithm merges information from various passive microwave

319 sensors of low Earth orbit satellites and infrared sensors on geostationary satellites to

320 create a high-precision precipitation dataset (Kubota et al. 2007). The GSMaP dataset

321 is available in near-real-time, post-real-time, and reanalysis versions. The near-real- 
322 time versions consists of two datasets: the GSMaP Near Real Time (GSMaP_NRT) and

323 GSMaP Gauge Near Real Time (GSMaP_Gauge_NRT) datasets. The post-real-time

324 versions are the GSMaP Moving Vector with Kalman filter (GSMaP_MVK) and

325 GSMaP_Gauge datasets. Finally, the reanalysis versions are the GSMaP_NRT and

326 GSMaP_Gauge_NRT datasets. This study used the GSMaP_MVK version 7 dataset,

327 which has a temporal resolution of 1 hour, spatial resolution of $0.1^{\circ} \times 0.1^{\circ}$, worldwide

328 coverage $\left(60^{\circ} \mathrm{N}\right.$ to $\left.60^{\circ} \mathrm{S}\right)$, and contains data from 2014 to the present. A previous

329 assessment of daily rainfall by using 52 rain gauges in the Philippines from 1998 to

3302015 revealed that the GSMaP_MVK dataset had a lower level of bias than the TRMM

331 and CMORPH datasets did (Ramos et al. 2016). The hourly GSMaP_MVK version 7

332 dataset can be downloaded from the website of the JAXA

333 (ftp://rainmap:Niskur+1404@ hokusai.eorc.jaxa.jp/standard/v7/hourly/).

\subsubsection{PERSIANN Dataset}

The PERSIANN dataset was established by the Center for Hydrometeorology and

336 Remote Sensing at the University of California, Irvine, in association with NASA and

337 the Global Network on Water and Development Information for Arid Lands of the

338 United Nations Educational, Scientific and Cultural Organization. The PERSIANN

339 retrieval algorithm is primarily based on integrated infrared imagery from

340 geosynchronous satellites, with forecasts generated by an artificial neural network to 
341 transform infrared imagery into global rainfall data (Sorooshian et al. 2000).

342 PERSIANN includes four precipitation datasets, namely the PERSIANN, the

343 PERSIANN-Cloud Classification System (PERSIANN-CCS), the PERSIANN-

344 Climate Data Record (PERSIANN-CDR), and PERSIANN Dynamic Infrared Rain

345 Rate near-real-time (PDIR-Now) datasets. PERSIANN contains hourly rainfall

346 estimates from March 2000 to the present with a spatial resolution of $0.25^{\circ}$ and global

347 coverage $\left(60^{\circ} \mathrm{N}-60^{\circ} \mathrm{S}\right)$. PERSIANN-CCS contains hourly rainfall data from January

3482003 to the present with worldwide coverage and a spatial resolution of $0.04^{\circ}$.

349 PERSIANN-CDR contains daily global rainfall data from January 1983 to the present

350 at a spatial resolution of $0.25^{\circ}$. PDIR-Now contains real-time global precipitation

351 estimates from March 2000 to the present at a spatial resolution of $0.04^{\circ}$. All the

352 PERSIANN datasets are accessible and have been widely used for various studies by

353 researchers and professionals in the fields of climate, hydrology, water resource

354 management, and disaster modeling. This study used the PERSIANN-CCS

355 precipitation dataset, which is available online at https://chrsdata.eng.uci.edu/. The

356 spatial resolution of PERSIANN-CCS is higher than that of all the other aforementioned

357 SPDs; thus, the PERSIANN-CCS dataset can be used to examine variations in rainfall

358 in small areas (Rivera et al. 2018). 


\subsubsection{Wind Data}

The wind data used in this study was ERA5, which is a grid reanalysis dataset

361 obtained from the European Centre for Medium-Range Weather Forecasts (ECMWF).

362 ERA5 contains the latest ECMWF atmosphere, land surface, and ocean reanalysis data

363 for global climate monitoring (Hersbach et al. 2020). Through reanalysis, model data

364 containing observations from around the world can be integrated into a complete and

365 worldwide consistent dataset (Olauson, 2018; Ramon et al. 2019; Hersbach et al. 2020).

366 ERA5 is frequently used in various applications and outperforms previous reanalysis

367 methods. It provides long-term (1979 to present) hourly estimates of variables on

368 pressure levels at a spatial resolution of $0.25^{\circ}$. This study used the components $u$ and $v$

369 of the wind dataset at a pressure level of $925-850 \mathrm{hPa}$. The aforementioned dataset can

370 be downloaded from https://cds.climate.copernicus.eu/cdsapp\#!/dataset/reanalysis-

371 era5-pressure-levels?tab=form.

\subsection{Methods}

A point-to-grid comparison was performed to compare the point-based rain gauge measurement data with the grid satellite precipitation dataset and grid reanalysis wind 
378 effect by comparing the precipitation estimates with the rain gauge measurements. The

379 comparison between SPDs estimates and rain gauge measurements was carried out

380 when the rain gauge is within R34 during the passing of the storm. The half-hourly

381 IMERG estimation and hourly GSMaP and PERSIANN estimation data were converted

382 into 3-hour rainfall data so that their temporal resolution matched that of the rain gauge

383 measurements. Only a few data points were missing from both the rain gauge stations

384 and SPDs, and they were excluded from the analysis. The 3-hour rainfall estimates

385 obtained by the SPDs were assessed as functions of rainfall intensity. The 3-hour

386 rainfall intensities for all precipitation datasets were categorized into the following five

387 groups: 0-5 mm/3 hours (light rain events), $5-15 \mathrm{~mm} / 3$ hours (moderate rain events),

388 15-25 mm/3 hours (heavy rain events), $25-50 \mathrm{~mm} / 3$ hours (very heavy rain events),

389 and $>50 \mathrm{~mm} / 3$ hours (extreme rain events). The performance of the SPDs in terms of

390 the terrain effect was evaluated by dividing the rain gauge stations into two elevation

391 categories: $\leq 1000 \mathrm{~m}$ (low altitude) and >1000 m (high altitude). The evaluation of the

392 SPD performance in terms of wind velocity was conducted by dividing wind speed into

393 the following five categories: $0-5,5-10,10-15,15-20,20-25$, and $\geq 25 \mathrm{~m} / \mathrm{s}$. The

394 distribution of the SPD performance in terms of wind direction was modeled as a wind

395 rose, in which wind direction was divided into eight categories: north $(\mathrm{N})$, northeast 
396 (NE), east (E), southeast (SE), south (S), southwest (SW), west (W), and northwest $397(\mathrm{NW})$.

The performance of the SPDs was evaluated by conducting a quantitative analysis

399 of two categories of validation statistics. The first statistical category was continuous

400 statistics, which describe the differences between satellite rainfall magnitude and

401 ground rainfall station measurements and include bias ratio (BR), correlation

402 coefficient $(R)$, mean error (ME), and root mean square error (RMSE). BR refers to the

403 tendency of SPDs to underestimate or overestimate rainfall compared with the rain

404 gauge station measurements. The perfect score for BR is 1. A BR below 1 indicates that

405 the satellite datasets tend to underestimate rainfall compared with the ground rainfall

406 measurements, and a BR above 1 indicates that the satellite datasets tend to

407 overestimate rainfall. The parameter $R$ measures the strength of the linear association

408 between the satellite rainfall estimates and the ground-based observations. A value of

4091 is the ideal score for $R$. ME indicates the average error in rainfall measurements

410 between the SPDs and the ground-based observations. RMSE reflects the average

411 deviation in absolute magnitude between the SPD data and the ground-based

412 observations. The ideal value of ME and RSME is $0 . \mathrm{RB}, R$, ME, and RMSE were

413 computed using the following equations (Ebert 2007; Tang et al. 2016; Liu et al. 2020a):

$414 \quad \mathrm{BR}=\frac{S_{i}}{G_{i}}$, 


$$
R=\frac{\sum_{i=1}^{N}\left(S_{i}-\bar{S}\right)\left(G_{i}-\bar{G}\right)}{\sqrt{\sum_{i=1}^{N}\left(S_{i}-\bar{S}\right)^{2}} \sqrt{\sum_{i=1}^{N}\left(G_{i}-\bar{G}\right)^{2}}}
$$

$$
\mathrm{ME}=\frac{1}{N} \sum_{i=1}^{N}\left(S_{i}-G_{i}\right)
$$

$$
\mathrm{RMSE}=\sqrt{\frac{1}{N} \sum_{i=1}^{N}\left(S_{i}-G_{i}\right)^{2}}
$$

418 where $S_{i}$ represents a satellite rainfall estimate, $G_{i}$ represents the corresponding

419 ground-based rainfall measurement, $\bar{S}$ indicates the average of the satellite rainfall 420 estimates, $\bar{G}$ represents the average of the ground-based rainfall measurements, $N$ 421 represents the total number of data points, and $i$ represents the number of the sample. of SPDs to detect an accurately/inaccuratelyamount of rainfall. This category includes

424 volumetric hit index (VHI), volumetric false alarm ratio (VFAR), and volumetric 425 critical success index (VCSI). VHI provides information regarding the volume of 426 rainfall accurately detected by the SPDs relative to the volume of rainfall accurately 427 detected by the satellites and the missing observations. VFAR represents the volume of 428 false rainfall detected by the SPDs relative to the sum of rainfall detected by the SPDs.

429 VCSI represents the overall measure of volumetric performance. VHI, VFAR, and 430 VCSI range from 0 to 1 , with the ideal score for VHI and VCSI being 1 and the ideal 431 score for VFAR being 0 . The equations for the volumetric indices are as follows 432 (Aghakouchak and Mehran 2013; Ayehu et al. 2018; Liu et al. 2020a): 


$$
\mathrm{VHI}=\frac{\sum_{\mathrm{i}=1}^{\mathrm{N}}\left(\mathrm{S}_{\mathrm{i}} \mid\left(\mathrm{S}_{\mathrm{i}}>\mathrm{t} \& \mathrm{G}_{\mathrm{i}}>\mathrm{t}\right)\right)}{\sum_{\mathrm{i}=1}^{\mathrm{N}}\left(\mathrm{S}_{\mathrm{i}} \mid\left(\mathrm{S}_{\mathrm{i}}>\mathrm{t} \& \mathrm{G}_{\mathrm{i}}>\mathrm{t}\right)\right)+\sum_{\mathrm{i}=1}^{\mathrm{N}}\left(\mathrm{G}_{\mathrm{i}} \mid\left(\mathrm{S}_{\mathrm{i}}<\mathrm{t} \& \mathrm{G}_{\mathrm{i}}>\mathrm{t}\right)\right)},
$$

$$
\operatorname{VFAR}=\frac{\sum_{\mathrm{i}=1}^{\mathrm{N}}\left(\mathrm{S}_{\mathrm{i}} \mid\left(\mathrm{S}_{\mathrm{i}}>\mathrm{t} \& \mathrm{G}_{\mathrm{i}} \leq \mathrm{t}\right)\right)}{\sum_{\mathrm{i}=1}^{\mathrm{N}}\left(\mathrm{S}_{\mathrm{i}} \mid\left(\mathrm{S}_{\mathrm{i}}>\mathrm{t} \& \mathrm{G}_{\mathrm{i}}>\mathrm{t}\right)\right)+\sum_{\mathrm{i}=1}^{\mathrm{N}}\left(\mathrm{S}_{\mathrm{i}} \mid\left(\mathrm{S}_{\mathrm{i}}>\mathrm{t} \& \mathrm{G}_{\mathrm{i}} \leq \mathrm{t}\right)\right)},
$$

$$
\operatorname{VCSI}=\frac{\sum_{\mathrm{i}=1}^{\mathrm{N}}\left(\mathrm{S}_{\mathrm{i}} \mid\left(\mathrm{S}_{\mathrm{i}}>\mathrm{t} \& \mathrm{G}_{\mathrm{i}}>\mathrm{t}\right)\right)}{\sum_{\mathrm{i}=1}^{\mathrm{N}}\left(\mathrm{S}_{\mathrm{i}} \mid\left(\mathrm{S}_{\mathrm{i}}>\mathrm{t} \& \mathrm{G}_{\mathrm{i}}>\mathrm{t}\right)\right)+\sum_{\mathrm{i}=1}^{\mathrm{N}}\left(\mathrm{G}_{\mathrm{i}} \mid\left(\mathrm{S}_{\mathrm{i}} \leq \mathrm{t} \& \mathrm{G}_{\mathrm{i}}>\mathrm{t}\right)\right)+\sum_{\mathrm{i}=1}^{\mathrm{N}}\left(\mathrm{S}_{\mathrm{i}} \mid\left(\mathrm{S}_{\mathrm{i}}>\mathrm{t} \& \mathrm{G}_{\mathrm{i}} \leq \mathrm{t}\right)\right)},
$$

where $t$ represents the threshold value of $15 \mathrm{~mm} / 3$ hours.

\section{Results and Discussion}

The ability of the SPDs to estimate rainfall during heavy precipitation events caused by typhoons was evaluated in terms of rain rate intensity, elevation, and wind

441 velocity by using continuous statistics (i.e., BR, $R, \mathrm{ME}$, and RMSE) and volumetric 442 indices (i.e., VHI, VFAR, and VCSI). High $R$, VHI, and VCSI values; low ME, RMSE, 443 and VFAR values; and BR values close to 1 indicated a high performance level.

\subsection{Performance of SPDs During Typhoon Events}


$451(0.39-0.63)$ and PERSIANN (0.38-0.73) datasets for almost all the typhoons (Sarika,

452 Nock-ten, Doksuri, and Mangkhut). However, the PERSIANN dataset exhibited a

453 stronger agreement with the rain gauge observations $(R=0.73)$ than did the other

454 satellite rainfall datasets during Typhoon Haima. Huang et al. (2019) revealed that the

$455 R$ value for IMERG Final Run version 5 dataset was approximately $0.4-0.63$ for six

456 typhoon events in southern China. The current study confirmed that the latest version

457 of the IMERG dataset exhibits increased agreement with the rain gauge observations

458 for higher $R$ values.

Table 2 presents a summary of the overall quantitative evaluation of the SPDs and

460 rain gauge measurements during the five typhoon events. The statistic metric summary

461 indicates that three satellite rainfall datasets exhibited different behaviors. This result

462 might have been caused by the complex typhoon structures, different tracks of the

463 typhoons, the structure of the atmosphere, the diverse topographic conditions, and

464 heterogeneous rainfall conditions on the spatiotemporal scale (Huang et al. 2019). The

465 GSMaP dataset substantially overestimated rainfall for all typhoon events compared

466 with the rain gauge data, yielding positive ME (1.75-7.68 $\mathrm{mm} / 3$ hours) and BR values

467 (1.22-1.73). ME and BR values greater than 1 were obtained for the aforementioned

468 dataset. A previous study found that GSMaP overestimated the daily extreme 
469 precipitation over the Western Himalayas (Parida et al. 2017). Both the IMERG and

470 PERSIANN datasets underestimated rainfall compared with the rain gauge data,

471 yielding negative ME and BR values for all typhoon events. The underestimation of the

472 IMERG dataset in this study is in agreement with the findings of other studies that have

473 applied this dataset to evaluate rainfall in southern China during typhoons Mawar,

474 Pakhar, Hato, and Merbok on a cumulative scale (Huang et al. 2019). In this study, the

475 IMERG dataset outperformed the GSMaP and PERSIANN datasets in terms of ME,

476 BR, and RMSE for all typhoon events except the Doksuri typhoon, for which the ME

477 and BR of the IMERG dataset were marginally higher than those of the PERSIANN

478 dataset.

479 In terms of the ability of the SPDs to detect heavy precipitation events, the GSMaP

480 dataset achieved the highest scores for VHI but the lowest scores for VFAR. The

481 IMERG dataset achieved the highest scores for VFAR (Sarika, Haima, Doksuri, and

482 Mangkhut) and VCSI (Sarika, Haima, Nock-ten, Doksuri, and Mangkhut). The

483 PERSIANN dataset achieved the highest scores for VFAR during the Nock-ten typhoon.

484 To demonstrate the performance of three SPDs more comprehensively, Figure 3

485 presents a performance diagram that displays an overview of the statistics that indicate

486 how well the three SPDs detected heavy precipitation events caused by typhoons in

487 terms of VHI, VFAR, VCSI, and BR. Such a performance diagram was proposed by 
Roebber to create a visual framework of the association among multiple aspects of model performance (Roebber 2009). VHI is represented on the $y$-axis; success ratio (1 - VFAR) is represented on the $x$-axis; BR is represented by the dotted lines beginning 491 at the origin, where the diagonal dotted line represents no bias; and VCSI is represented 492 by the dashed contour lines. The best performance is in the top right corner of the 493 diagram and along the diagonal dotted line, where BR is 1. The IMERG dataset 494 achieved the best performance among the SPDs during typhoons Sarika, Haima, Nock495 ten, Doksuri, and Mangkhut. This result can probably be attributed to the high temporal 496 resolution of the IMERG dataset when determining the frequency of precipitation 497 events, which allows this dataset to detect the regional variance in subdaily precipitation 498 more effectively (Dezfuli et al. 2017; Liu et al. 2020a).

500 weather phenomena and the hydrological cycle (Liu et al. 2016a; Liu et al. 2016b;

501 Huang et al. 2019). Heavy rainfall in a short period can cause natural disasters, such as 502 floods and landslides. Figure 4 presents plots of the average 3-hour rainfall in the 503 Philippines during the five typhoon events. The highest values for average 3-hour 504 rainfall were different for each typhoon event probably due to the differences in 505 atmospheric conditions and the complexity of the typhoon structure. In general, the patterns of temporal variations of precipitation found using the three SPDs were in good 
agreement with that of rain gauge measurements. The GSMaP dataset exhibited

508 superior agreement with the rainfall station observations during peak rainfall. The

509 IMERG and PERSIANN datasets considerably underestimated rainfall during rainfall

510 peaks in the typhoon events.

\subsection{Performance of SPDs Under Different Rainfall Intensities}

The BR values between the rain gauge station measurements and the data of the

513 IMERG, GSMaP, and PERSIANN datasets for different rainfall rate intervals were

514 derived. Figure 5 presents a boxplot of the BRs for the IMERG, GSMaP, and

515 PERSIANN datasets during the five typhoon events under different rainfall intensities.

516 The bottom and top of the boxplot represent the first and the third quartiles of the data,

517 respectively. The line inside the boxplot represents the second quartile and median. The

518 maximum and minimum values of the data are represented by the lines at the top and

519 bottom of the whisker, respectively. Outliers are any line not within the whisker. The

520 datasets tended to overestimate rainfall during light to moderate rain (0-5 and 5-15

$521 \mathrm{~mm} / 3$ hours) and tended to underestimate rainfall during heavy to extreme rain (15-25,

$52225-50$, and $>50 \mathrm{~mm} / 3$ hours). This result is consistent with those of other studies, one

523 of which confirmed that the IMERG and GSMaP datasets overestimate the frequency

524 of light to moderate rainfall events $(1-10 \mathrm{~mm})$ and underestimate the frequency of

525 extreme rainfall events (>0 mm) (Liu et al. 2020a). Another study revealed that the 
GSMaP and PERSIANN datasets underestimate the frequency of extreme rainfall (75-

$527100 \mathrm{~mm} /$ day) (Palharini et al. 2020). Fang et al. (2019) discovered that the IMERG

528 dataset underestimates extreme precipitation. The underestimation of the SPDs during

529 heavy to extreme rainfall might be caused by the interpolation process of classifying

530 heavy rainfall (Fang et al. 2019). The IMERG dataset exhibited a satisfactory ability to

531 detect moderate rainfall events $(5-15 \mathrm{~mm} / 3$ hours $)$, whereas the GSMaP dataset

532 exhibited superior performance to the other two datasets in detecting heavy to extreme

533 rainfall $(15-25,25-50$, and $>50 \mathrm{~mm} / 3$ hours $)$ during the five typhoon events in the

534 Philippines.

535 The performance of the SPDs was also assessed at various rainfall thresholds: 5,

53615,25 , and $50 \mathrm{~mm} / 3$ hours. Figure 6 presents the performance diagram for the IMERG,

537 GSMaP, and PERSIANN datasets in terms of the volumetric indices (VHI, 1 - VFAR,

538 VCSI, and BR) for 3-hour precipitation under various rainfall thresholds. The ability of

539 these three SPDs to detect precipitation decreased with an increase in rainfall. VHI and

540 VCSI decreased and VFAR increased with increasing rainfall intensity. These results

541 indicated that the satellite sensors performed poorly in terms of detecting precipitation

542 in extreme rainfall events (Sun et al. 2016; Huang et al. 2019). The IMERG dataset

543 exhibited a stronger rainfall detection ability than did the other two datasets when the

544 rainfall was 5,15 , and $25 \mathrm{~mm} / 3$ hours. However, the GSMaP dataset exhibited the 
545 strongest ability to detect rainfall when the rainfall was $50 \mathrm{~mm} / 3$ hours. The

546 PERSIANN dataset exhibited the weakest ability to detect rainfall at all rainfall rates.

547 Research demonstrated that the PERSIANN dataset did not perform well in the

548 detection of daily moderate rainfall events $(10 \mathrm{~mm})$ and daily heavy rainfall events (25

$549 \mathrm{~mm}$ ) in the Wei River Basin in China (Liu et al. 2019). The poor performance of

550 PERSIANN dataset may due to the fact that the precipitation estimation algorithm of

551 PERSIANN is not calibrated with the rain gauge observations. The IMERG dataset is

552 calibrated using the monthly rainfall dataset from the Deutscher Wetterdienst Global

553 Precipitation Climatology Centre (Nguyen et al. 2018; Huffman et al. 2019).

\section{$554 \quad 4.3$ Performance of the SPDs at Different Elevations}

The variation in rainfall in the island area is caused by orographic uplift and the

556 complexity of topography (Lee et al. 2014). Topography has a prominent effect on

557 precipitation (Chen et al. 2020). The altitudes of the rain gauge stations used in this

558 study were divided into two categories: $\leq 1000 \mathrm{~m}$ (low altitude) and $>1000 \mathrm{~m}$ (high

559 altitude). Table 3 presents an assessment of statistical metrics for the IMERG, GSMaP,

560 and PERSIANN datasets for 3-hour precipitation estimates at different elevations.

561 According to the BR and ME values, the SPDs tended to overestimate rainfall at low

562 elevation and underestimate rainfall at high elevations. The IMERG dataset had the

563 highest $R$ and lowest RMSE values at both high and low altitudes. The IMERG dataset 
564 exhibited superior performance at low altitudes because it had the best scores in the 565 continuous statistical analysis (BR, $R, \mathrm{ME}$, and RMSE). The BR of the GSMaP dataset 566 was 0.96 at high altitudes, which indicates that this dataset had $4 \%$ bias compared with 567 the rain gauge measurements. The high BR of the GSMaP dataset at high elevations 568 was possibly caused by the inclusion of a topographic dataset from the Shuttle Radar 569 Topography Mission 30 Arc Second to classify orographic and nonorographic rainfall 570 (Yamamoto and Shige 2015).

571 Satellite rainfall estimates performed better in detecting heavy precipitation at high

572 altitudes than at low altitudes. This result might have been caused by orographic uplift 573 (Tang et al. 2018). In terms of the ability of SPDs to detect heavy rainfall at different 574 elevations, the PERSIANN dataset exhibited the lowest VHI and VCSI values at low 575 altitudes, whereas the GSMaP dataset exhibited the worse VFAR values at low 576 elevations (Table 3). The GSMaP dataset exhibited the highest VHI at both altitudes; 577 the IMERG dataset exhibited the best VFAR values at low altitudes; and the 578 PERSIANN dataset had a perfect VFAR value at high altitudes. The performance 579 diagram summarizes the three SPDs' ability to detect heavy rainfall accurately at 580 different altitudes (Figure 7). The GSMaP dataset outperformed the other datasets in 581 terms of the ability to detect heavy rainfall at high elevations, whereas the IMERG 582 dataset outperformed the other datasets at low elevations. The PERSIANN dataset 
583 performed poorly at both elevations probably because its rainfall estimation algorithm

584 does not contain a terrain component (Nguyen et al. 2018).

585

586

587

588

589

590

591 effect of wind velocity on the ability of SPDs to detect heavy precipitation caused by to overestimate rainfall, with a distribution of frequency concentrated on positive MEs $601(0-20 \mathrm{~mm} / 3$ hours $)$ and a BR above 1. The IMERG dataset exhibited superior

\subsection{Performance of the SPDs Under Different Wind Velocities}

The levels of infrastructural and environmental damage caused by typhoon events are influenced by wind intensity. High wind intensity is also associated with heavy rainfall, which is another hazard of typhoon events (Bloemendaal et al. 2020). In a previous study, the rainfall caused by typhoon events was forecasted using satellite estimates of rainfall data, typhoon intensity, and wind vectors (Kidder et al. 2005). The typhoon events should be investigated. In this study, the averages of the wind vector components $u$ and $v$ from the ECMWF at a pressure level of $925-850 \mathrm{hPa}$, which is observed at the considered rain gauge stations, were processed into wind speed and direction, respectively. The frequency distribution indicates the relationship between wind speed and the continuous performance statistics (Figure 8). The IMERG and PERSIANN datasets underestimated rainfall compared with the gauge station measurements, yielding a high-frequency concentration of negative MEs $(-20-0 \mathrm{~mm} / 3$ hours) and a BR below 1 for the distribution of wind speed. The GSMaP dataset tended 
agreement with the rain gauge observations at different wind speeds, with the

603 distribution frequency of $R$ ranging from 0.4 to 1 . For the PERSIANN and GSMaP

604 datasets, the distribution frequency of $R$ ranged from 0.1 to 1 and from 0 to 0.9 ,

605 respectively. The frequency distributions of RMSE at each wind speed for the IMERG

606 and PERSIANN datasets ranged from 0 to $30 \mathrm{~mm} / 3$ hours, whereas those for the

607 GSMaP dataset ranged from 0 to $40 \mathrm{~mm} / 3$ hours. Among the three SPDs, the IMERG

608 dataset was the most consistent with the rain gauge measurements in terms of having

609 the most continuous statistical parameters at the different wind speeds. The distribution

610 frequencies of ME, RMSE, $R$, and BR for the IMERG dataset were concentrated around

611 the near-perfect value for the continuous statistics.

612 The distribution percentage of each volumetric index presented in Figure 9 was

613 used to describe the association between wind speed and the ability of the SPDs to

614 detect heavy rainfall events caused by typhoons. In terms of the VHI distribution, the

615 GSMaP dataset exhibited the best performance, followed by the IMERG and

616 PERSIANN dataset. The GSMaP dataset yielded high frequency distribution for a VHI

617 range of $0.9-1.0$ in the wind speed range of $7.5-12.5 \mathrm{~m} / \mathrm{s}$. The IMERG dataset exhibited

618 high frequency distribution for a VHI range of 0.9-1.0 in the wind speed range of 10-

$61912.5 \mathrm{~m} / \mathrm{s}$, and the PERSIANN dataset exhibited high frequency distribution for a VHI

620 range of $0.5-0.6$ in the wind speed range of $7.5-10 \mathrm{~m} / \mathrm{s}$. In terms of false rainfall 
621 estimates, the IMERG dataset outperformed the GSMaP and PERSIANN datasets. The

622 IMERG dataset had a high-frequency distribution at a lower VFAR than did the other

623 SPDs. The comprehensive evaluation of the volumetric index performance indicates

624 that compared with the other SPDs, the IMERG dataset exhibited a stronger ability to

625 detect heavy rainfall at various wind speeds.

626 Complex topography and mountainous regions with orographic convection and

627 low-troposphere winds represent a challenge in rainfall estimation by satellites (Shige

628 et al. 2013). Luzon, which is located in the northern part of the Philippines, has a

629 complex and mountainous topography and often experiences typhoons. Therefore, the

630 influence of wind in mountainous areas on the performance of satellite rainfall

631 estimations must be studied. Wind direction and speed data were collected from a

632 selected rainfall measurement station on Luzon island (Figure 1b) and analyzed in the

633 form of wind roses. A wind rose is a graph that represents the distribution of wind speed

634 and direction for an area over a certain period. Figure 10a presents a wind rose for the

635 eastern part of the mountainous region, and Figure 10k presents a wind rose for the

636 western part of the region. A total of $75 \%$ of the winds are in the NW direction in the

637 eastern part of the mountainous region, and the most frequent wind speed interval is

$63810-15 \mathrm{~m} / \mathrm{s}$, which accounts for $50 \%$ of the wind speeds. In the eastern part of the

639 mountainous region, wind speed is primarily in the intervals of $10-15,0-5,5-10$, and 
$640 \quad 15-20 \mathrm{~m} / \mathrm{s}$. A total of $41 \%$ of the winds in the western part of the mountainous region

641 are in the north direction, and the predominant wind speed is $>25 \mathrm{~m} / \mathrm{s}$, which accounts

642 for $23 \%$ of the wind speeds. In the western part of the mountainous region, wind speed

643 is predominantly in the intervals of $>25,20-25$, and $15-20 \mathrm{~m} / \mathrm{s}$. This finding indicates

644 that wind speeds are higher in the western part of the mountainous region than in its

645 eastern part.

646 Figure $10(\mathrm{~b}-\mathrm{j})$ depicts the distribution of volumetric statistical values for the

647 different wind direction and wind speed ranges in the eastern part of the mountainous

648 region of Luzon. Figure 10(1-t) illustrates the distribution of volumetric statistical

649 values for the western part of the mountainous region. The IMERG dataset

650 outperformed the other SPDs in detecting heavy rainfall events in the eastern part of

651 the mountainous region, as indicated by the distributions of VHI, VFAR, and VCSI.

652 Compared with the other SPDs, the IMERG dataset exhibited superior distributions of

653 VHI, VFAR, and VCSI under almost all ranges of wind speed and wind direction. The

654 GSMaP dataset yielded high VHI and VCSI values for most wind speed ranges and

655 wind directions in the western part of the mountainous region. This result indicated that

656 the GSMaP dataset exhibited a strong performance in detecting heavy rainfall events

657 under high wind speeds. However, the VFAR values of the GSMaP dataset were higher

658 than those of the other SPDs, which were approximately $0.5-1$ for the western part of 
659 the mountainous area. This result indicates that the GSMaP algorithm generates a large

660 quantity of false rainfall data under high wind speeds. Among the three SPDs, the

661 GSMaP and IMERG datasets demonstrated a stronger ability to detect heavy rainfall

662 events in terms of the effect of wind velocity in the western and eastern parts of the

663 mountainous region, respectively.

\section{5. Conclusion}

Assessing the performance of SPDs during heavy precipitation caused by

666 typhoons is crucial for utilizing them and evaluating their algorithms. Studies have

667 analyzed the ability of SPDs to detect heavy precipitation caused by typhoon events on

668 daily, monthly, seasonal, annual, and cumulative scales. This study performed a

669 subdaily (3-hour) assessment of the performance of three SPDs, namely the IMERG,

670 GSMaP, and PERSIANN datasets, during five typhoon-related heavy precipitation

671 events in the Philippines between 2016 and 2018. This assessment was performed

672 through a point-to-pixel comparison by using continuous and volumetric statistical

673 validation indices to assess the R34 values of the typhoons, rainfall intensity, the terrain,

674 and wind velocity effects. This study yielded the following results:

675 1. The IMERG dataset exhibited good agreement with the rain gauge 676 observations and performed considerably well in detecting rainfall during the 

superior agreement with the rainfall station observations during peak rainfall.

679

680
2. The precipitation datasets tended to overestimate rainfall in light to moderate rainfall events and underestimate rainfall in heavy to extreme rainfall events. The IMERG dataset exhibited a strong ability to detect rainfall in moderate rainfall events (5-15 mm/3 hours), whereas the GSMaP dataset exhibited superior performance in detecting rainfall during heavy to extreme rain events $(15-25,25-50$, and $>50 \mathrm{~mm} / 3$ hours) during the five typhoon events in the Philippines.

3. The GSMaP dataset outperformed the other SPDs in terms of ability to detect heavy rainfall at high elevations, whereas the IMERG dataset outperformed the other SPDs in terms of ability to detect rainfall at low elevations.

4. Wind direction and wind speed influence the ability of SPDs to detect rainfall. The IMERG dataset exhibited a strong ability to detect heavy rainfall under various wind speeds. The GSMaP dataset exhibited a stronger ability to detect heavy rainfall events in terms of wind velocity in the western part of the mountainous region than in its eastern part. By contrast, the IMERG dataset exhibited better performance in the eastern part of the mountainous region than in its western part. 
697 challenge in archipelagos with complex terrain or mountainous areas. In this study, the

698 IMERG and GSMaP datasets demonstrated a promising ability to detect heavy

699 precipitation caused by typhoon events. An in-depth investigation is required before the

700 IMERG and GSMaP datasets are applied to tropical-cyclone-related studies.

701 Developments in SPD algorithms are expected to focus on improving the detection of

702 extreme rainfall and the use of hourly rain gauge observations for calibration. In the

703 most recent study, the cloud microphysical and optical properties, such as cloud-top

704 altitude, cloud optical thickness and effective cloud droplet radius could be retrieved

705 accuractly from the observation of geostationary satellite (e.g, Liu et al., 2020b), and

706 all the cloud properties are associated with the precipitation as already known before.

707 Additional studies might be including the analysis of cloud properties and other typhoon

708 event samples to investigate the precipitation processes and quantify the source of error 709 in SPDs.

710

\section{Declarations}

712 Availability of data and materials: Please contact author for data requests.

713 - Funding: This work was supported by the Ministry of Science and Technology of

714 Taiwan (grants MOST 109-2625-M-008-013, MOST 109-2111-M-008-025, 
- Competing interests: The authors declare that they have no competing interests. the data analysis and wrote the original draft. All the authors discussed the results and reviewed, edited, and commented on the manuscript. All the authors read and approved the final version of this manuscript for publication. PERSIANN datasets. We also acknowledge PAGASA, Department of Science and Technology, Republic of the Philippines, for its support in obtaining gauge station rainfall data across the Philippines. PA was supported by the International Ph.D.

726 Program in Environmental Science and Technology (University System of Taiwan)

727 at National Central University, Taiwan. This work was supported by the Ministry

728 of Science and Technology of Taiwan (grants MOST 109-2625-M-008-013, MOST 109-2111-M-008-025, MOST 110-2625-M-008-002, and MOST 110110-01). 


\section{References}

Aghakouchak A, Mehran A (2013) Extended contingency table: Performance metrics for satellite observations and climate model simulations. Water Resources Research 49:7144-7149. https://doi.org/10.1002/wrcr.20498

Ayehu GT, Tadesse T, Gessesse B, Dinku T (2018) Validation of new satellite rainfall products over the Upper Blue Nile Basin, Ethiopia. Atmospheric Measurement Techniques 11:1921-1936. https://doi.org/10.5194/amt-11-1921-2018

Bagtasa G (2017) Contribution of tropical cyclones to rainfall in the Philippines. Journal of Climate 30:3621-3633. https://doi.org/10.1175/JCLI-D-16-0150.1

Bautista L (2011) Philippine territorial boundaries: internal tensions, colonial baggage, ambivalent conformity. JATI : Journal of Southeast Asian Studies 16:35-53

Beck HE, Van Dijk AIJM, Levizzani V, et al (2017) MSWEP: 3-hourly 0.25 global gridded precipitation (1979-2015) by merging gauge, satellite, and reanalysis data. Hydrology and Earth System Sciences 21:589-615. https://doi.org/10.5194/hess21-589-2017

Bell JL, Sloan LC, Snyder MA (2004) Regional changes in extreme climatic events: A future climate scenario. Journal of Climateat 17:81-87. https://doi.org/10.1175/1520-0442(2004)017<0081:RCIECE $>2.0 . C O ; 2$

Bloemendaal N, de Moel H, Muis S, et al (2020) Estimation of global tropical cyclone wind speed probabilities using the STORM dataset. Scientific Data 7:1-11. https://doi.org/10.1038/s41597-020-00720-x

Chen C, Li Z, Song Y, et al (2020) Performance of multiple satellite precipitation estimates over a typical arid mountainous area of China: Spatiotemporal patterns and extremes. Journal of Hydrometeorology 21:533-550. https://doi.org/10.1175/JHM-D-19-0167.1

Chen S, Hong Y, Cao Q, et al (2013) Performance evaluation of radar and satellite rainfalls for Typhoon Morakot over Taiwan: Are remote-sensing products ready for gauge denial scenario of extreme events? Journal of Hydrology 506:4-13. https://doi.org/10.1016/j.jhydrol.2012.12.026

Chen TC, Wu CC (2016) The remote effect of Typhoon Megi (2010) on the heavy rainfall over Northeastern Taiwan. Monthly Weather Review 144:3109-3131. https://doi.org/10.1175/MWR-D-15-0269.1

Cheung K, Yu Z, Elsberry RL, et al (2018) Recent Advances in Research and Forecasting of Tropical Cyclone Rainfall. Tropical Cyclone Research and Review 
768

769

770

771

772

773

774

775

776

777

778

779

780

781

782

783

784

785

786

787

788

789

790

791

792

793

794

795

796

797

798

799

800

Cinco TA, de Guzman RG, Ortiz AMD, et al (2016) Observed trends and impacts of tropical cyclones in the Philippines. International Journal of Climatology 36:4638-4650. https://doi.org/10.1002/joc.4659

Dezfuli AK, Ichoku CM, Huffman GJ, et al (2017) Validation of IMERG Precipitation in Africa. Journal of Hydrometeorology 18:2817-2825. https://doi.org/10.1175/JHM-D-17-0139.1

Duan Z, Liu J, Tuo Y, et al (2016) Evaluation of eight high spatial resolution gridded precipitation products in Adige Basin (Italy) at multiple temporal and spatial scales. Science of the Total Environment 573:1536-1553. https://doi.org/10.1016/j.scitotenv.2016.08.213

Ebert EE (2007) Methods for Verifying Satellite Precipitation Estimates. In: Measuring Precipitation from Space: EURAINSAT and the Future. Springer, pp 345-356

Fang J, Yang W, Luan Y, et al (2019) Evaluation of the TRMM 3B42 and GPM IMERG products for extreme precipitation analysis over China. Atmospheric Research 223:24-38. https://doi.org/10.1016/j.atmosres.2019.03.001

Fenta AA, Yasuda H, Shimizu K, et al (2018) Evaluation of satellite rainfall estimates over the Lake Tana basin at the source region of the Blue Nile River. Atmospheric Research 212:43-53. https://doi.org/10.1016/j.atmosres.2018.05.009

Funk C, Peterson P, Landsfeld M, et al (2015) The climate hazards infrared precipitation with stations - A new environmental record for monitoring extremes. Scientific Data 2:1-21. https://doi.org/10.1038/sdata.2015.66

Hersbach H, Bell B, Berrisford P, et al (2020) The ERA5 global reanalysis. Quarterly Journal of the Royal Meteorological Society 146:1999-2049. https://doi.org/10.1002/qj.3803

Hon K-K (2020) Tropical cyclone track prediction using a large-area WRF model at the Hong Kong Observatory. Tropical Cyclone Research and Review 9:67-74. https://doi.org/10.1016/j.tcrr.2020.03.002

Hong Y, Alder R, Huffman G (2006) Evaluation of the potential of NASA multi-satellite precipitation analysis in global landslide hazard assessment. Geophysical Research Letters 33:1-5. https://doi.org/10.1029/2006GL028010

Hou AY, Kakar RK, Neeck S, et al (2014) The global precipitation measurement mission. Bulletin of the American Meteorological Society 95:701-722. https://doi.org/10.1175/BAMS-D-13-00164.1 
Hsu K, Gao X, Sorooshian S, Gupta H V. (1997) Precipitation Estimation from Remotely Sensed Information Using Artificial Neural Networks. Journal of Applied Meteorology 36:1176-1190. https://doi.org/10.1175/15200450(1997)036<1176:pefrsi $>2.0 . c 0 ; 2$

Huang C, Hu J, Chen S, et al (2019) How Well Can IMERG Products Capture Typhoon Extreme Precipitation Events over Southern China? Remote Sensing 11:70. https://doi.org/10.3390/rs11010070

Huang X, Wang D, Liu Y, et al (2018) Evaluation of extreme precipitation based on satellite retrievals over China. Frontiers of Earth Science 12:846-861. https://doi.org/10.1007/s11707-017-0643-2

Huang YC, Lin YL (2014) A study on the structure and precipitation of Morakot (2009) induced by the Central Mountain Range of Taiwan. Meteorology and Atmospheric Physics 123:115-141. https://doi.org/10.1007/s00703-013-0290-4

Huffman GJ, Bolvin DT, Braithwaite D, et al (2019) Algorithm Theoretical Basis Document (ATBD) Version 06 NASA Global Precipitation Measurement (GPM) Integrated Multi-satellitE Retrievals for GPM (IMERG). National Aeronautics and Space Administration (NASA) 1-34

Jamandre CA, Narisma GT (2013) Spatio-temporal validation of satellite-based rainfall estimates in the Philippines. Atmospheric Research 122:599-608. https://doi.org/10.1016/j.atmosres.2012.06.024

Javanmard S, Yatagai A, Nodzu MI, et al (2010) Comparing high-resolution gridded precipitation data with satellite rainfall estimates of TRMM-3B42 over Iran. Advances in Geosciences 25:119-125. https://doi.org/10.5194/adgeo-25-1192010

Ji X, Li Y, Luo X, et al (2020) Evaluation of bias correction methods for APHRODITE data to improve hydrologic simulation in a large Himalayan basin. Atmospheric Research 242:104964. https://doi.org/10.1016/j.atmosres.2020.104964

Jones SC, Harr PA, Abraham J, et al (2003) The extratropical transition of tropical cyclones: Forecast challenges, current understanding, and future directions. Weather and Forecasting 18:1052-1092. https://doi.org/10.1175/15200434(2003)018<1052:TETOTC $>2.0 . \mathrm{CO} ; 2$

Joyce RJ, Janowiak JE, Arkin PA, Xie P (2004) CMORPH: A Method that Produces Global Precipitation Estimates from Passive Microwave Microwave and Infrared Data at High Spatial and Temporal Resolution. Journal of Hydrometeorology 5:487-502. https://doi.org/10.1175/1525- 
Kidder SQ, Kusselson SJ, Knaff JA, et al (2005) The tropical rainfall potential (TRaP) technique. Part I: Description and examples. Weather and Forecasting 20:456-464. https://doi.org/10.1175/WAF860.1

Kimball SK (2008) Structure and evolution of rainfall in numerically simulated

Knapp KR, Kruk MC, Levinson DH, et al (2010) The international best track archive 844 landfalling hurricanes. Monthly Weather Review 136:3822-3847. https://doi.org/10.1175/2008MWR2304.1

Lee K-O, Uyeda H, Lee D-I (2014) Microphysical structures associated with enhancement of convective cells over Mt. Halla, Jeju Island, Korea on 6 July 2007. Atmospheric Research 135-136:76-90. https://doi.org/10.1016/j.atmosres.2013.08.012

Levizzani V, Cattani E (2019) Satellite remote sensing of precipitation and the terrestrial water cycle in a changing climate. Remote Sensing 11: https://doi.org/10.3390/rs11192301

Li Z, Yang D, Hong Y (2013) Multi-scale evaluation of high-resolution multi-sensor blended global precipitation products over the Yangtze River. Journal of Hydrology 500:157-169. https://doi.org/10.1016/j.jhydrol.2013.07.023

Liu C.-Y., Aryastana P, Liu G-R, Huang W-R (2020a) Assessment of satellite precipitation product estimates over Bali Island. Atmospheric Research 244:1-14. https://doi.org/10.1016/j.atmosres.2020.105032

Liu C.-Y., C.-H.Chiu, P. H.Lin, and M. Min (2020b) Comparison of Cloud-Top Property Retrievals From Advanced Himawari Imager, MODIS, CloudSat/CPR, CALIPSO/CALIOP, and Radiosonde. J. Geophys. Res. Atmos., 125, https://doi.org/10.1029/2020JD032683.

Liu C.-Y., Kuo S-C, Lim A, et al (2016a) Optimal Use of Space-Borne Advanced 
Infrared and Microwave Soundings for Regional Numerical Weather Prediction. Remote Sensing 8:816. https://doi.org/10.3390/rs8100816

Liu C.-Y., Li J, Ho S-P, et al (2016b) Retrieval of Atmospheric Thermodynamic State From Synergistic Use of Radio Occultation and Hyperspectral Infrared Radiances Observations. IEEE Journal of Selected Topics in Applied Earth Observations and Remote Sensing 9:744-756. https://doi.org/10.1109/JSTARS.2015.2444274

Liu J, Xia J, She D, et al (2019) Evaluation of six satellite-based precipitation products and their ability for capturing characteristics of extreme precipitation events over a climate transition area in China. Remote Sensing 11:1-21. https://doi.org/10.3390/rs11121477

Lonfat M, Rogers R, Marchok T, Marks FD (2007) A parametric model for predicting hurricane rainfall. Monthly Weather Review 135:3086-3097. https://doi.org/10.1175/MWR3433.1

Nashwan MS, Shahid S, Dewan A, et al (2020) Performance of five high resolution 886 satellite-based precipitation products in arid region of Egypt: An evaluation. Atmospheric Research 236:104809. https://doi.org/10.1016/j.atmosres.2019.104809

Nguyen P, Ombadi M, Sorooshian S, et al (2018) The PERSIANN family of global satellite precipitation data: A review and evaluation of products. Hydrology and Earth System Sciences 22:5801-5816. https://doi.org/10.5194/hess-22-5801-2018

Okamoto K, Ushio T, Iguchi T, et al (2005) The Global Satellite Mapping of Precipitation (GSMaP) project. International Geoscience and Remote Sensing Symposium (IGARSS) 5:3414-3416.

Olauson J (2018) ERA5: The new champion of wind power modelling? Renewable 897 PAGASA Climate of the Philippines. 898 899 http://bagong.pagasa.dost.gov.ph/information/climate-philippines\#. Accessed 10 Oct 2020

Palharini RSA, Vila DA, Rodrigues DT, et al (2020) Assessment of the extreme 901

Parida BR, Behera SN, Bakimchandra O, et al (2017) Evaluation of satellite-derived 904 rainfall estimates for an extreme rainfall event over Uttarakhand, Western Himalayas. Hydrology 4:1-18. https://doi.org/10.3390/hydrology4020022 
Pham NTT, Vu HH (2020) Characteristics of Tropical Cyclone Precipitating System Along Central Coastal Region of Vietnam by TRMM and GSMAP Data. In: The 10th International Conference on Asian and Pacific Coasts (APAC) 2019. Springer Nature Singapore Pte Ltd., Hanoi, pp 87-91

Pombo S, de Oliveira RP (2015) Evaluation of extreme precipitation estimates from TRMM in Angola. Journal of Hydrology 523:663-679. https://doi.org/10.1016/j.jhydrol.2015.02.014

Ramon J, Lledó L, Torralba V, et al (2019) What global reanalysis best represents nearsurface winds? Quarterly Journal of the Royal Meteorological Society 145:32363251. https://doi.org/10.1002/qj.3616

Ramos MD, Tendencia E, Espana K, et al (2016) Assessment of satellite precipitation products in the philippine archipelago. International Archives of the Photogrammetry, Remote Sensing and Spatial Information Sciences - ISPRS Archives XLI-B1:423-427. https://doi.org/10.5194/isprsarchives-XLI-B1-4232016

Rashid I, Parray AA, Romshoo SA (2018) Evaluating the Performance of Remotely Sensed Precipitation Estimates against In-Situ Observations during the September 2014 Mega-Flood in the Kashmir Valley. Asia-Pacific Journal of Atmospheric Sciences 55:209-219. https://doi.org/10.1007/s13143-018-0071-6

Rivera JA, Marianetti G, Hinrichs S (2018) Validation of CHIRPS precipitation dataset along the Central Andes of Argentina. Atmospheric Research 213:437-449. https://doi.org/10.1016/j.atmosres.2018.06.023

Roebber PJ (2009) Visualizing multiple measures of forecast quality. Weather and Forecasting 24:601-608. https://doi.org/10.1175/2008WAF2222159.1

Ross RJ, Kurihara Y (1995) A Numerical Study on Influences of Hurricane Gloria (1985) on the Environment. Monthly Weather Review 123:332-346. https://doi.org/10.1175/1520-0493(1995)123<0332:ANSOIO >2.0.CO;2

Setiawati MD, Miura F, Aryastana P (2016) Validation of Hourly GSMaP and ground base estimates of precipitation for flood monitoring in Kumamoto, Japan. In: Srivastava PK, Pandey PC, Kumar P, et al. (eds) Geospatial Technology for Water Resource Applications. CRC Press, Boca Raton : Taylor \& Francis, 2017., pp 130143

Shige S, Kida S, Ashiwake H, et al (2013) Improvement of TMI Rain Retrievals in Mountainous Areas. Journal of Applied Meteorology and Climatology 52:242254. https://doi.org/10.1175/JAMC-D-12-074.1 
Sorooshian S, Hsu KL, Gao X, et al (2000) Evaluation of PERSIANN system satellitebased estimates of tropical rainfall. Bulletin of the American Meteorological Society 81:2035-2046. https://doi.org/10.1175/15200477(2000)081<2035:EOPSSE>2.3.CO;2

Stampoulis D, Anagnostou EN, Nikolopoulos EI (2013) Assessment of high-resolution satellite-based rainfall estimates over the mediterranean during heavy precipitation events. Journal of Hydrometeorology 14:1500-1514. https://doi.org/10.1175/JHM-D-12-0167.1

Sun R, Yuan H, Liu X, Jiang X (2016) Evaluation of the latest satellite-gauge precipitation products and their hydrologic applications over the Huaihe River basin. Journal of Hydrology 536:302-319. https://doi.org/10.1016/j.jhydrol.2016.02.054

Tang G, Behrangi A, Long D, et al (2018) Accounting for spatiotemporal errors of gauges: A critical step to evaluate gridded precipitation products. Journal of Hydrology 559:294-306. https://doi.org/10.1016/j.jhydrol.2018.02.057

Tang G, Ma Y, Long D, et al (2016) Evaluation of GPM Day-1 IMERG and TMPA Version-7 legacy products over Mainland China at multiple spatiotemporal scales. Journal of Hydrology 533:152-167. https://doi.org/10.1016/j.jhydrol.2015.12.008

Tashima T, Kubota T, Mega T, et al (2020) Precipitation Extremes Monitoring Using the Near-Real-Time GSMaP Product. IEEE Journal of Selected Topics in Applied Earth Observations and Remote Sensing 13:5640-5651. https://doi.org/10.1109/jstars.2020.3014881

Ushio T, Sasashige K, Kubota T, et al (2009) A Kalman Filter Approach to the Global Satellite Mapping of Precipitation (GSMaP) from Combined Passive Microwave and Infrared Radiometric Data. Journal of the Meteorological Society of Japan 87A:137-151. https://doi.org/10.2151/jmsj.87A.137

Wang D, Wang X, Liu L, et al (2016) Evaluation of CMPA precipitation estimate in the evolution of typhoon-related storm rainfall in Guangdong, China. Journal of Hydroinformatics 18:1055-1068. https://doi.org/10.2166/hydro.2016.241

Wang Y, Wang Y, Fudeyasu H (2009) The role of Typhoon Songda (2004) in producing distantly located heavy rainfall in Japan. Monthly Weather Review 137:36993716. https://doi.org/10.1175/2009MWR2933.1

Weinkle J, Maue R, Pielke R (2012) Historical global tropical cyclone landfalls. Journal of Climate 25:4729-4735. https://doi.org/10.1175/JCLI-D-11-00719.1

Wu CC, Cheung KKW, Lo YY (2009) Numerical study of the rainfall event due to the 
interaction of typhoon Babs (1998) and the northeasterly monsoon. Monthly Weather Review 137:2049-2064. https://doi.org/10.1175/2009MWR2757.1

Wu H, Adler RF, Hong Y, et al (2012) Evaluation of Global Flood Detection Using Satellite-Based Rainfall and a Hydrologic Model. Journal of Hydrometeorology 13:1268-1284. https://doi.org/10.1175/jhm-d-11-087.1

Wu Y, Zhang Z, Huang Y, et al (2019) Evaluation of the GPM IMERG v5 and TRMM $3 \mathrm{~B} 42$ v7 precipitation products in the Yangtze River basin, China. Water (Switzerland) 11:. https://doi.org/10.3390/w11071459

Xie P, Arkin PA (1997) Global Precipitation: A 17-Year Monthly Analysis Based on Gauge Observations, Satellite Estimates, and Numerical Model Outputs. Bulletin of the American Meteorological Society 78:2539-2558. https://doi.org/10.1175/1520-0477(1997)078<2539:GPAYMA>2.0.CO;2

Yamamoto MK, Shige S (2015) Implementation of an orographic/nonorographic rainfall classification scheme in the GSMaP algorithm for microwave radiometers. Atmospheric Research 163:36-47. https://doi.org/10.1016/j.atmosres.2014.07.024

Yang MJ, Braun SA, Chen DS (2011) Water budget of Typhoon Nari (2001). Monthly Weather Review 139:3809-3828. https://doi.org/10.1175/MWR-D-10-05090.1

Yokoyama C, Takayabu YN (2008) A statistical study on rain characteristics of tropical cyclones using TRMM satellite data. Monthly Weather Review 136:3848-3862. https://doi.org/10.1175/2008MWR2408.1

Yu CK, Cheng LW (2013) Distribution and mechanisms of orographic precipitation associated with typhoon morakot (2009). Journal of the Atmospheric Sciences 70:2894-2915. https://doi.org/10.1175/JAS-D-12-0340.1

Yu Z, Yu H, Chen P, et al (2009) Verification of tropical cyclone-related satellite precipitation estimates in mainland China. Journal of Applied Meteorology and Climatology 48:2227-2241. https://doi.org/10.1175/2009JAMC2143.1

Zhang F, Weng Y, Kuo YH, et al (2010) Predicting typhoon morakot's catastrophic rainfall with a convection-permitting mesoscale ensemble system. Weather and Forecasting 25:1816-1825. https://doi.org/10.1175/2010WAF2222414.1 


\section{Tables}

1011 Table 1. Information regarding five typhoon events in the Philippines.

\begin{tabular}{|c|c|c|c|c|c|c|c|}
\hline $\begin{array}{l}\text { Name of } \\
\text { Typhoon }\end{array}$ & $\begin{array}{l}\text { Start Time } \\
\text { (UTC) }\end{array}$ & $\begin{array}{l}\text { End time } \\
\text { (UTC) }\end{array}$ & $\begin{array}{c}\text { Duration } \\
\text { (hours) }\end{array}$ & $\begin{array}{c}\text { Maximum } \\
\text { Wind } \\
\text { Speed } \\
\text { (knots) }\end{array}$ & $\begin{array}{l}\text { Number } \\
\text { of } \\
\text { stations }\end{array}$ & $\begin{array}{c}\text { Maximum } \\
\text { Actual } \\
\text { Rainfall Rate } \\
\text { (mm/3 } \\
\text { hours) }\end{array}$ & $\begin{array}{c}\text { Maximum } \\
\text { Cumulative } \\
\text { Actual } \\
\text { Rainfall } \\
\text { (mm) }\end{array}$ \\
\hline \multirow[t]{2}{*}{ Sarika } & 2016-10-14 & $2016-10-16$ & 45 & 95 & 31 & 167.0 & 629.5 \\
\hline & $15: 00$ & $12: 00$ & & & & & \\
\hline \multirow[t]{2}{*}{ Haima } & 2016-10-18 & $2016-10-20$ & 39 & 115 & 15 & 247.0 & 836.5 \\
\hline & $21: 00$ & $12: 00$ & & & & & \\
\hline \multirow[t]{2}{*}{ Nock-ten } & $2016-12-24$ & $2016-12-26$ & 45 & 105 & 16 & 183.0 & 284.0 \\
\hline & $12: 00$ & 9:00 & & & & & \\
\hline \multirow[t]{2}{*}{ Doksuri } & 2017-09-11 & $2017-09-12$ & 33 & 40 & 21 & 151.5 & 436.0 \\
\hline & $6: 00$ & $15: 00$ & & & & & \\
\hline \multirow[t]{2}{*}{ Mangkhut } & 2018-09-13 & 2018-09-15 & 51 & 148 & 40 & 93.5 & 344.0 \\
\hline & $18: 00$ & 21:00 & & & & & \\
\hline
\end{tabular}

1012

1013 
1014 Table 2. Statistical metric summary of the Integrated Merged MultisatellitE Retrievals 1015 for Global Precipitation Measurement (IMERG), Global Satellite Mapping of 1016 Precipitation (GSMaP), and Precipitation Estimation from Remotely Sensed 1017 Information Using Artificial Neural Networks (PERSIANN) datasets for the five 1018 typhoon events. Unit of the mean error (ME) and root mean square error (RMSE): $\mathrm{mm} / 3$ 1019 hours.

\begin{tabular}{|c|c|c|c|c|c|c|c|c|}
\hline $\begin{array}{l}\text { Name of } \\
\text { Typhoon }\end{array}$ & SPD & $\mathrm{BR}$ & $\mathrm{R}$ & $\mathrm{ME}$ & RMSE & VHI & VFAR & VCSI \\
\hline \multirow[t]{3}{*}{ Sarika } & IMERG & 0.95 & 0.72 & -2.06 & 12.51 & 0.67 & 0.29 & 0.52 \\
\hline & GSMaP & 1.73 & 0.62 & 2.08 & 16.31 & 0.77 & 0.52 & 0.41 \\
\hline & PERSIANN & 0.91 & 0.55 & -2.69 & 14.89 & 0.48 & 0.48 & 0.33 \\
\hline \multirow[t]{3}{*}{ Haima } & IMERG & 0.88 & 0.71 & -4.95 & 21.35 & 0.59 & 0.34 & 0.46 \\
\hline & GSMaP & 1.22 & 0.63 & 5.49 & 27.07 & 0.68 & 0.44 & 0.45 \\
\hline & PERSIANN & 0.81 & 0.73 & -7.99 & 22.41 & 0.51 & 0.38 & 0.39 \\
\hline \multirow[t]{3}{*}{ Nock-ten } & IMERG & 0.97 & 0.83 & -0.93 & 15.65 & 0.70 & 0.28 & 0.55 \\
\hline & GSMaP & 1.35 & 0.56 & 2.91 & 24.23 & 0.69 & 0.48 & 0.42 \\
\hline & PERSIANN & 0.73 & 0.68 & -4.02 & 17.36 & 0.60 & 0.18 & 0.53 \\
\hline \multirow[t]{3}{*}{ Doksuri } & IMERG & 0.89 & 0.64 & -3.60 & 14.60 & 0.55 & 0.38 & 0.42 \\
\hline & GSMaP & 1.42 & 0.39 & 7.68 & 28.00 & 0.56 & 0.60 & 0.30 \\
\hline & PERSIANN & 0.99 & 0.38 & -1.35 & 19.22 & 0.45 & 0.54 & 0.29 \\
\hline \multirow[t]{3}{*}{ Mangkhut } & IMERG & 0.97 & 0.68 & -0.40 & 12.44 & 0.57 & 0.41 & 0.41 \\
\hline & GSMaP & 1.29 & 0.57 & 1.75 & 14.37 & 0.67 & 0.48 & 0.41 \\
\hline & PERSIANN & 0.84 & 0.51 & -1.11 & 13.94 & 0.48 & 0.43 & 0.35 \\
\hline \multirow[t]{3}{*}{ All Typhoon } & IMERG & 0.93 & 0.72 & -2.39 & 15.31 & 0.62 & 0.34 & 0.47 \\
\hline & GSMaP & 1.40 & 0.55 & 3.98 & 22.00 & 0.67 & 0.50 & 0.40 \\
\hline & PERSIANN & 0.86 & 0.57 & -3.43 & 17.56 & 0.50 & 0.40 & 0.38 \\
\hline
\end{tabular}


1022 Table 3. Statistical metric summary of the IMERG, GSMaP, and PERSIANN datasets

1023 at different elevations. Unit of ME and RMSE: $\mathrm{mm} / 3$ hours.

\begin{tabular}{ccccccccc}
\hline Elevation & SPD & BR & R & ME & RMSE & VHI & VFAR & VCSI \\
\hline \multirow{2}{*}{ Low } & IMERG & 1.08 & 0.70 & 1.70 & 13.25 & 0.64 & 0.38 & 0.45 \\
& GSMaP & 1.43 & 0.55 & 3.57 & 19.12 & 0.66 & 0.54 & 0.38 \\
& PERSIANN & 1.09 & 0.52 & 1.94 & 15.59 & 0.52 & 0.50 & 0.34 \\
\multirow{2}{*}{ High } & IMERG & 0.71 & 0.81 & -6.78 & 17.79 & 0.54 & 0.23 & 0.47 \\
& GSMaP & 0.94 & 0.76 & -5.16 & 18.91 & 0.74 & 0.22 & 0.62 \\
& PERSIANN & 0.50 & 0.74 & -9.72 & 20.51 & 0.50 & 0.00 & 0.50 \\
\hline
\end{tabular}

1024

1025 
(a)

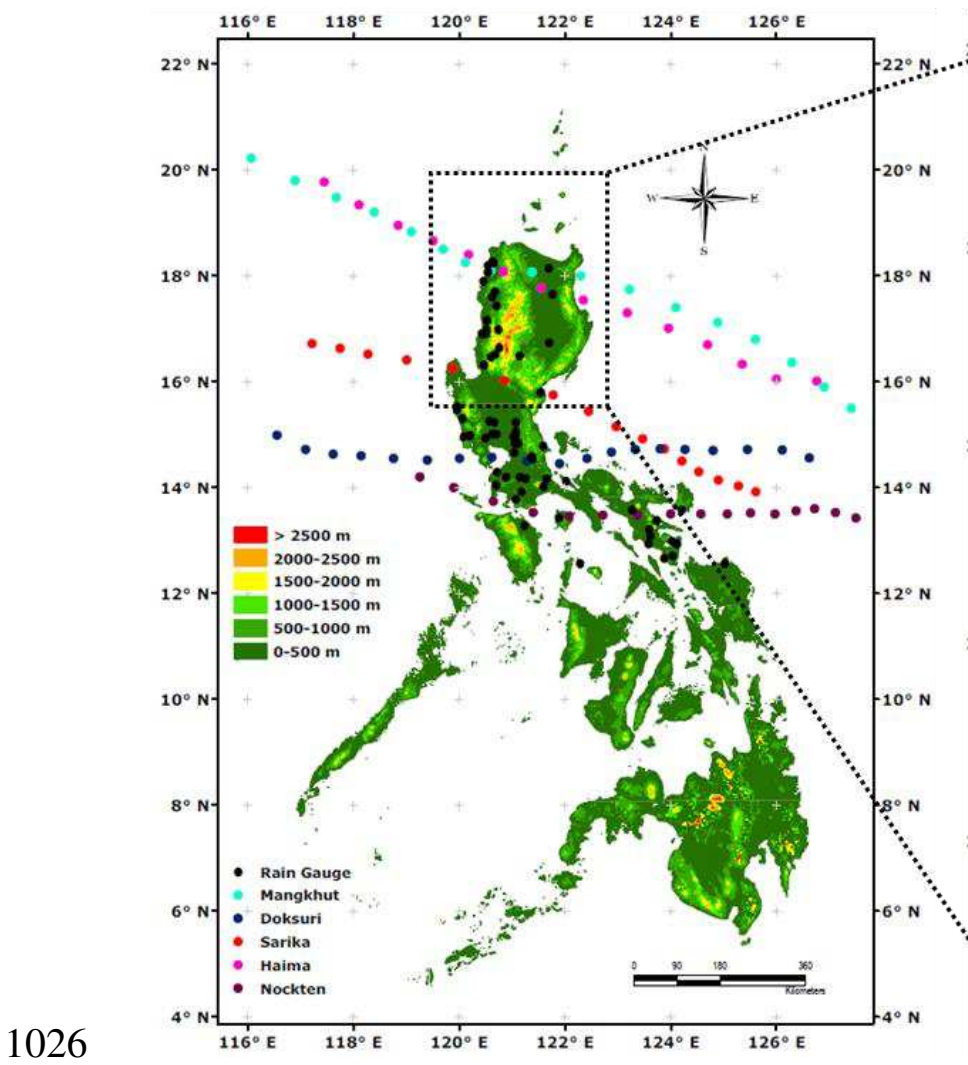

(b)

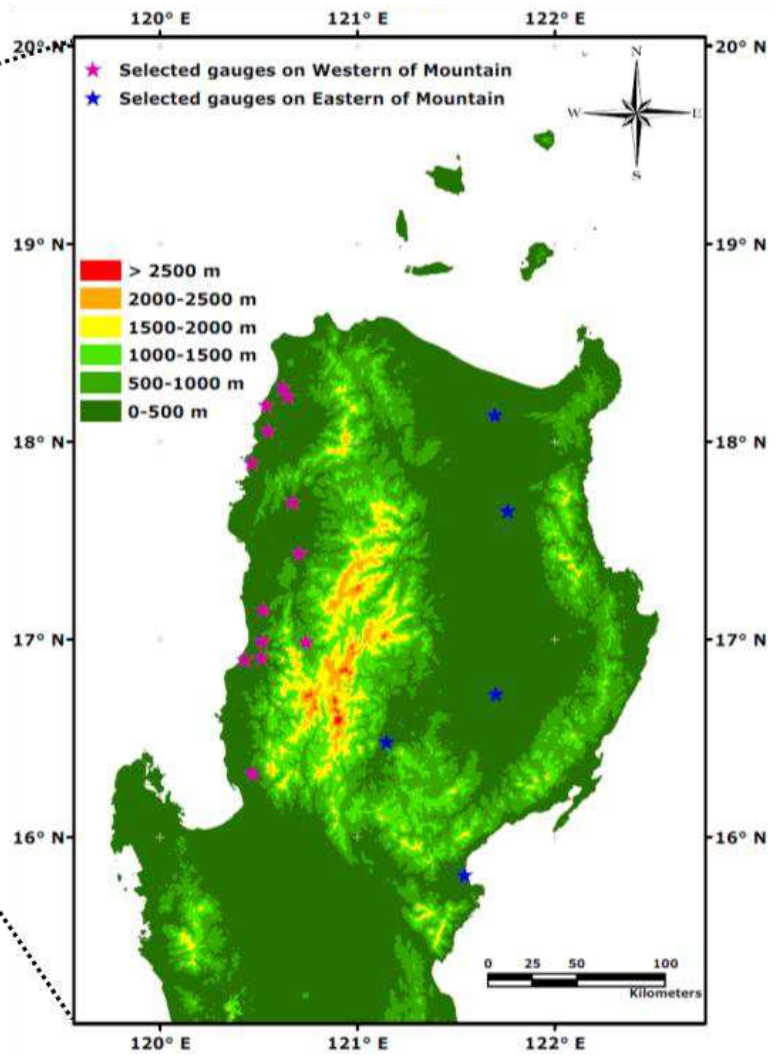

1027 Figure 1. (a) Map of the Philippines, including distribution of the rain gauge stations

1028 (black dots), terrain, and tracks of the five typhoons (colored dots). (b) Map of Luzon

1029 island, including the selected rain gauge stations (colored stars) and terrain. 
IMERG
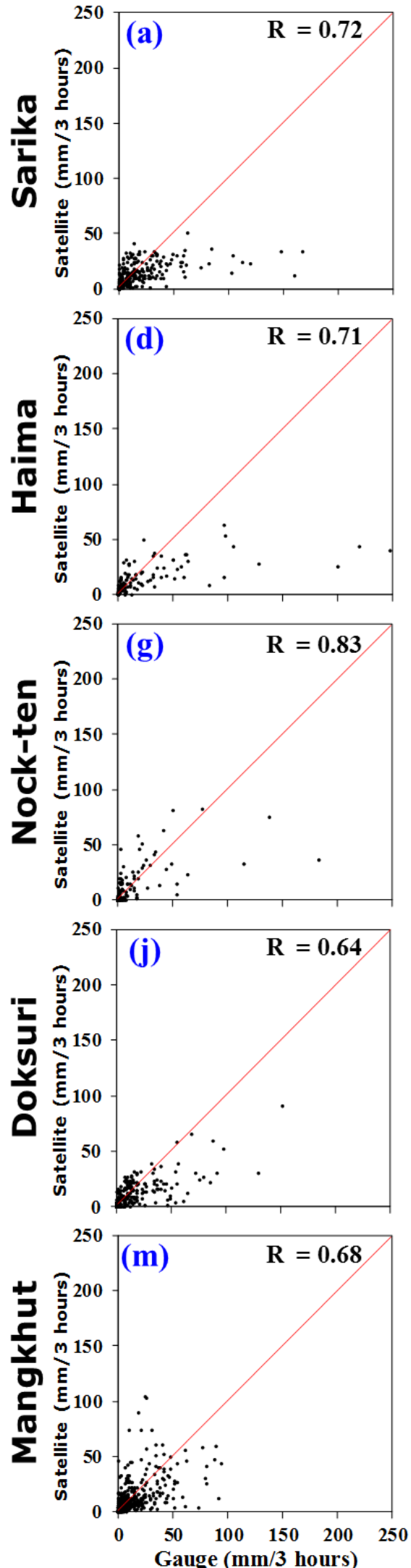

GSMaP
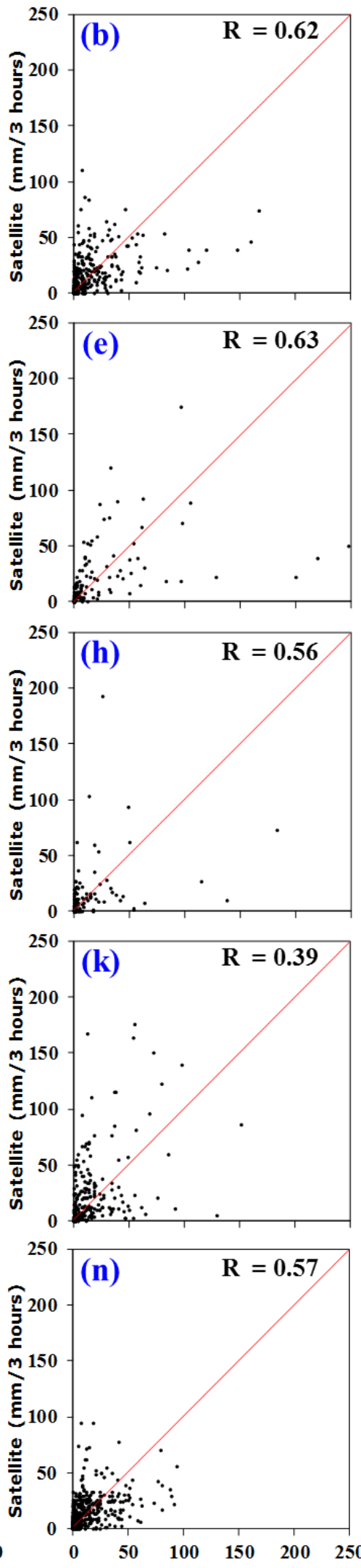

Gauge (mm/3 hours)
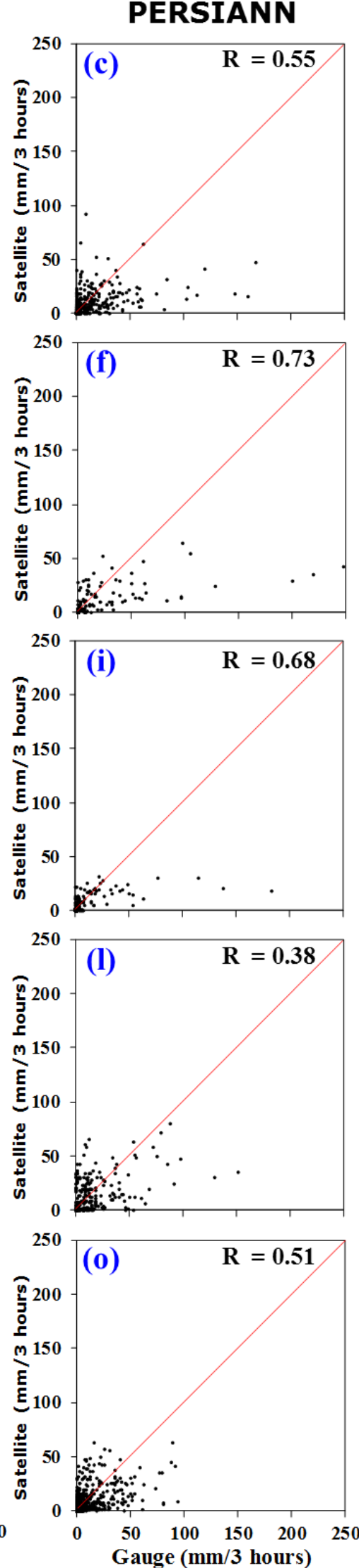

Figure 2. Scatter plot of rain gauge measurements for different satellite precipitation

1033 datasets (IMERG, GSMaP, and PERSIANN) during the five typhoon events: Sarika (a- 
$1034 \mathrm{c})$, Haima (d-f), Nock-ten ( $\mathrm{g}-\mathrm{i})$, Doksuri $(\mathrm{j}-\mathrm{l})$, and Mangkhut (m-o). The parameter $R$ 1035 represents the correlation coefficient. 


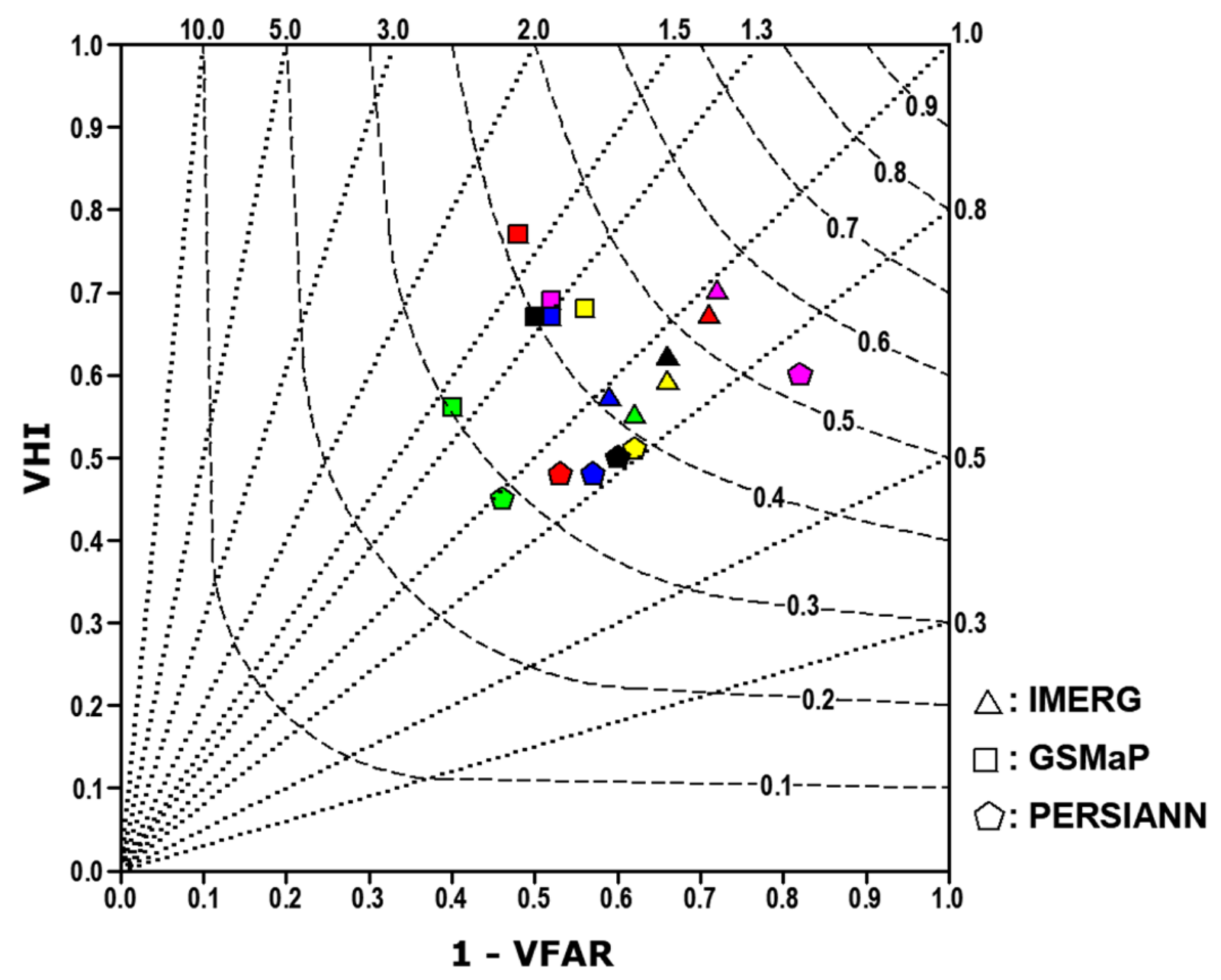

1036

1037 Figure 3. Performance diagram for the SPDs that represents their ability to detect

1038 rainfall during typhoon events. Different colors represent different typhoon events (red:

1039 Sarika; yellow: Haima; magenta: Nock-ten; green: Doksuri; blue: Mangkhut; and black:

1040 all typhoons).

1041 

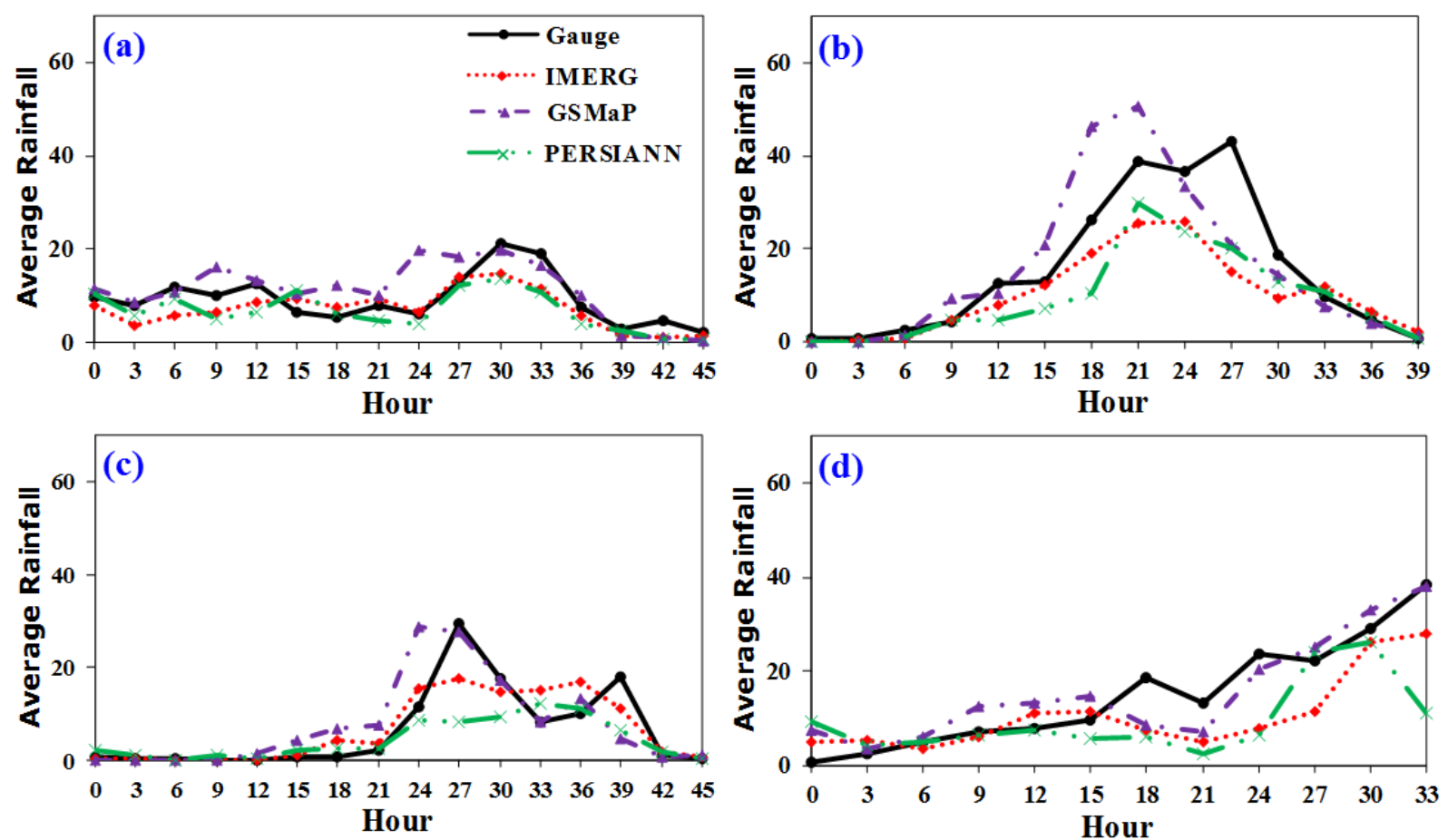

1042

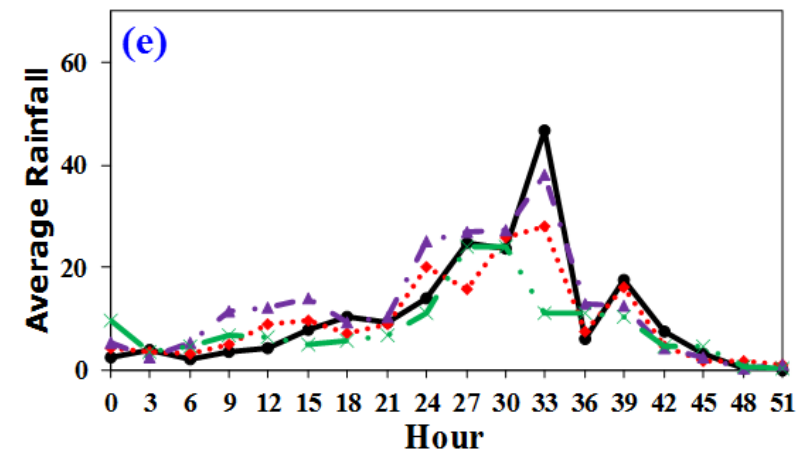

1043 Figure 4. Average 3-hour rainfall during the five typhoon events: (a) Sarika, (b) Haima, 1044 (c) Nock-ten, (d) Doksuri, and (e) Mangkhut. 

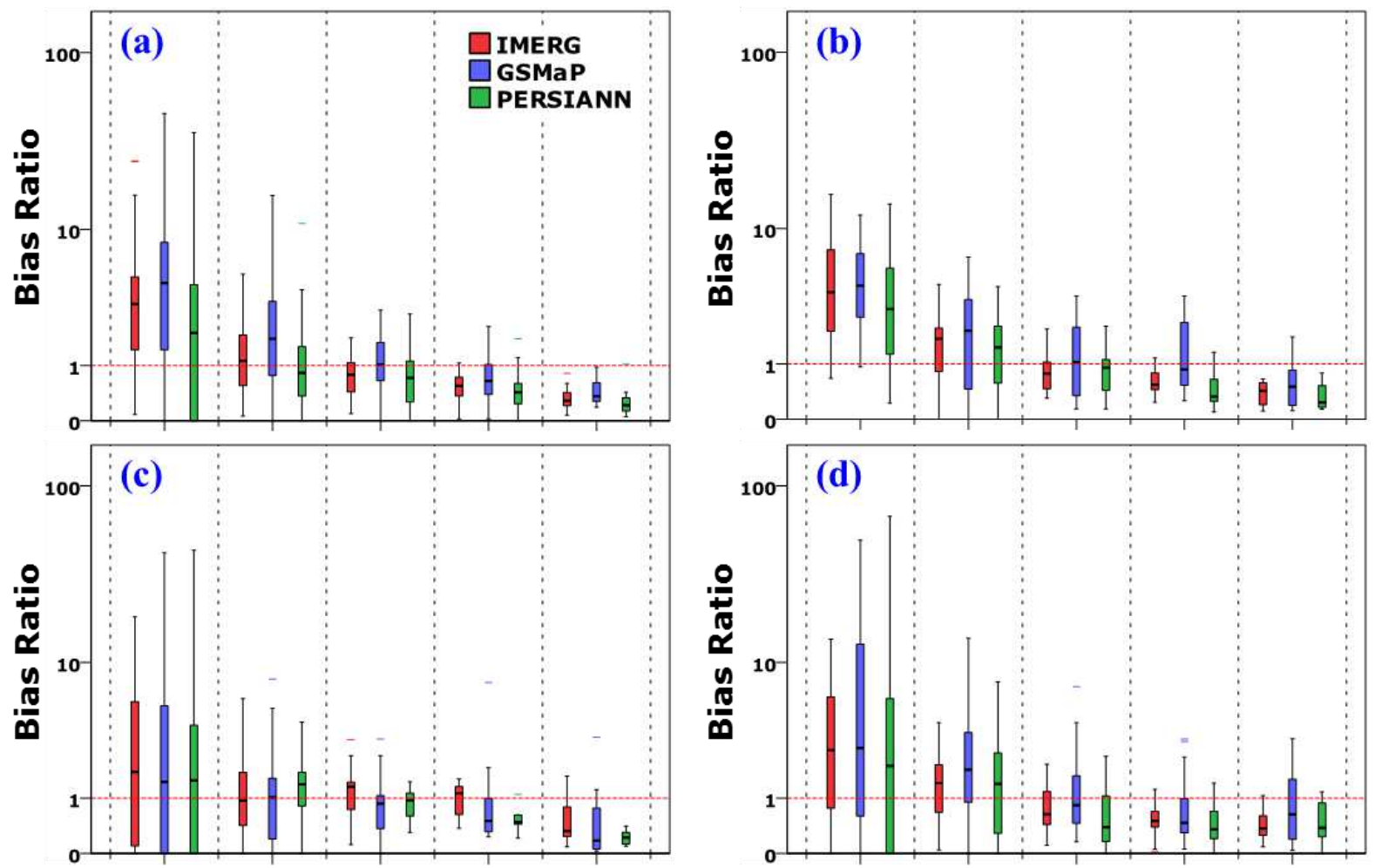

1046
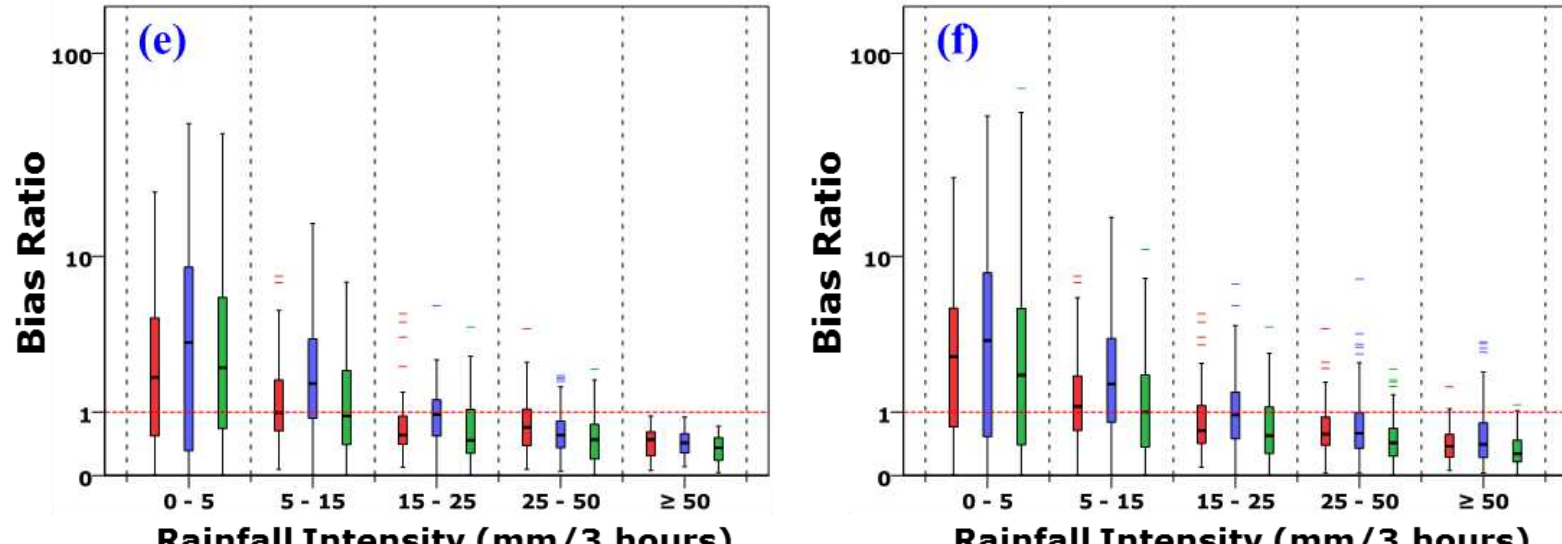

1047 Figure 5. Boxplot of the bias ratios (BRs) for different rainfall intensities for the IMERG, 1048 GSMaP, and PERSIANN datasets during the typhoon events: (a) Sarika, (b) Haima, (c)

1049 Nock-ten, (d) Doksuri, (e) Mangkhut, and (f) all typhoons. 


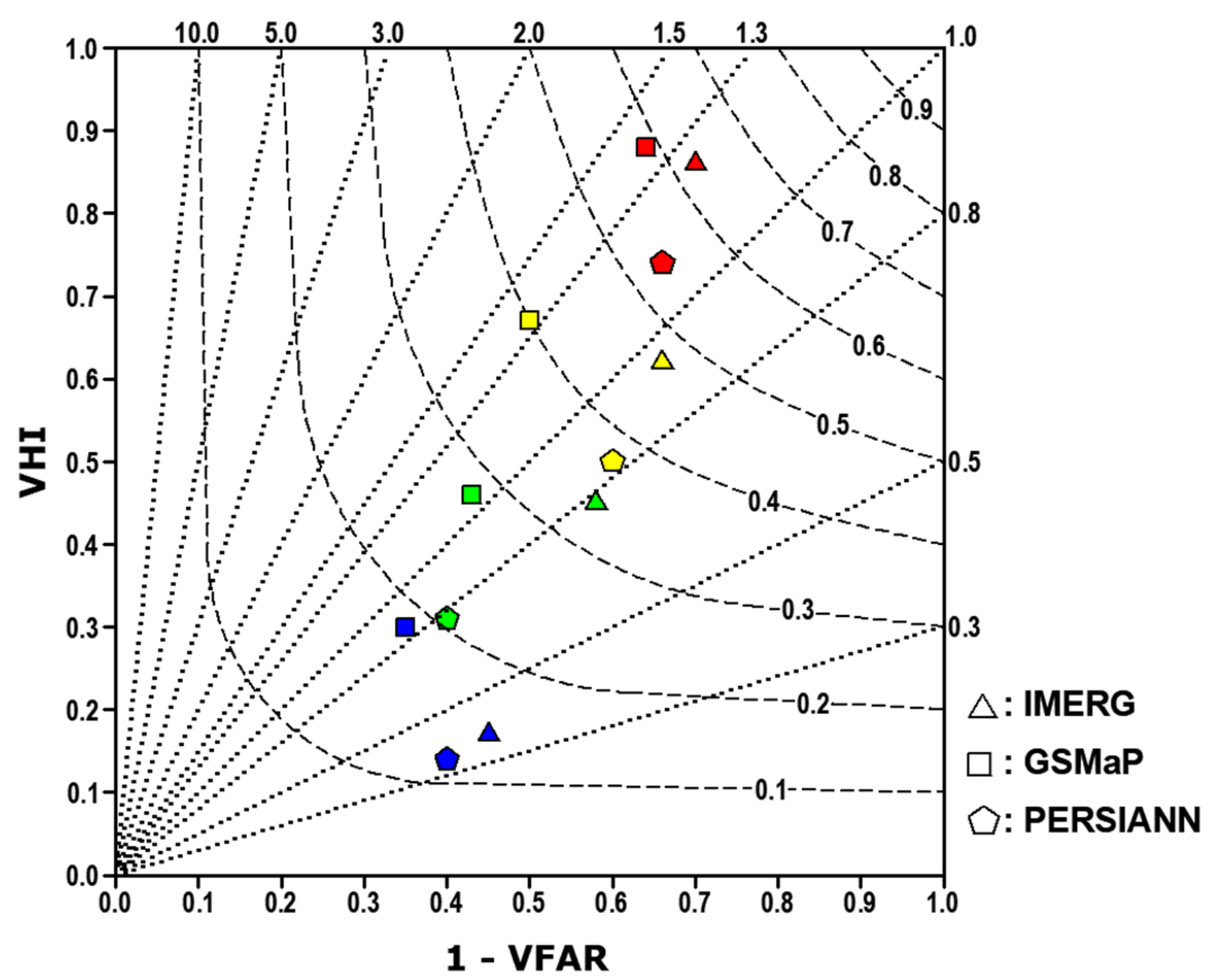

1051

1052 Figure 4. Performance diagram of the SPDs at different threshold values. Different

1053 colors represent different threshold values (red: $5 \mathrm{~mm} / 3$ hours; yellow: $15 \mathrm{~mm} / 3$ hours;

1054 green: $25 \mathrm{~mm} / 3$ hours; and blue: $50 \mathrm{~mm} / 3$ hours).

1055 


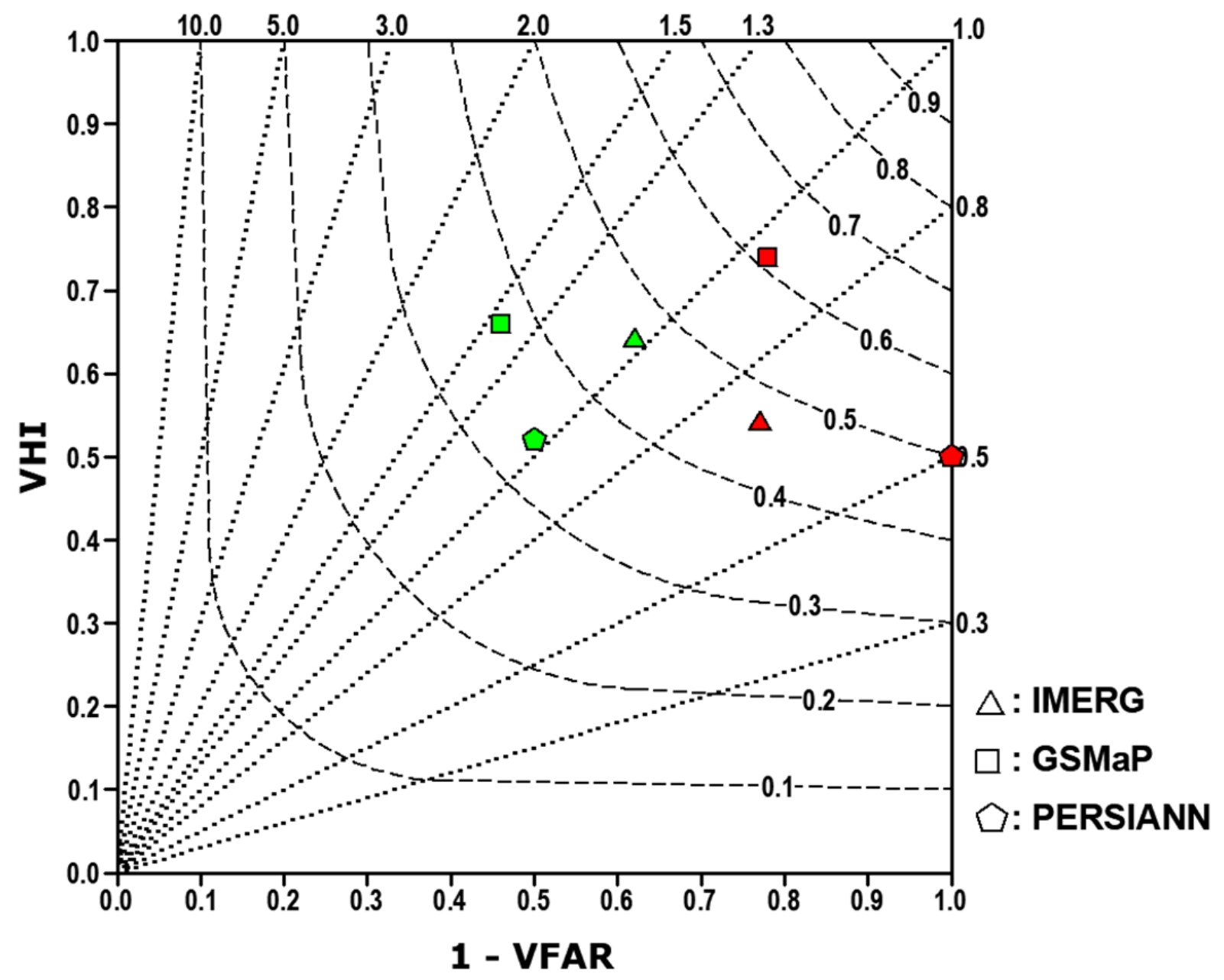

1056

1057 Figure 5. Performance diagram of the SPDs at different altitudes. Different colors 1058 represent different altitudes (green: low altitude and red: high altitude).

1059 

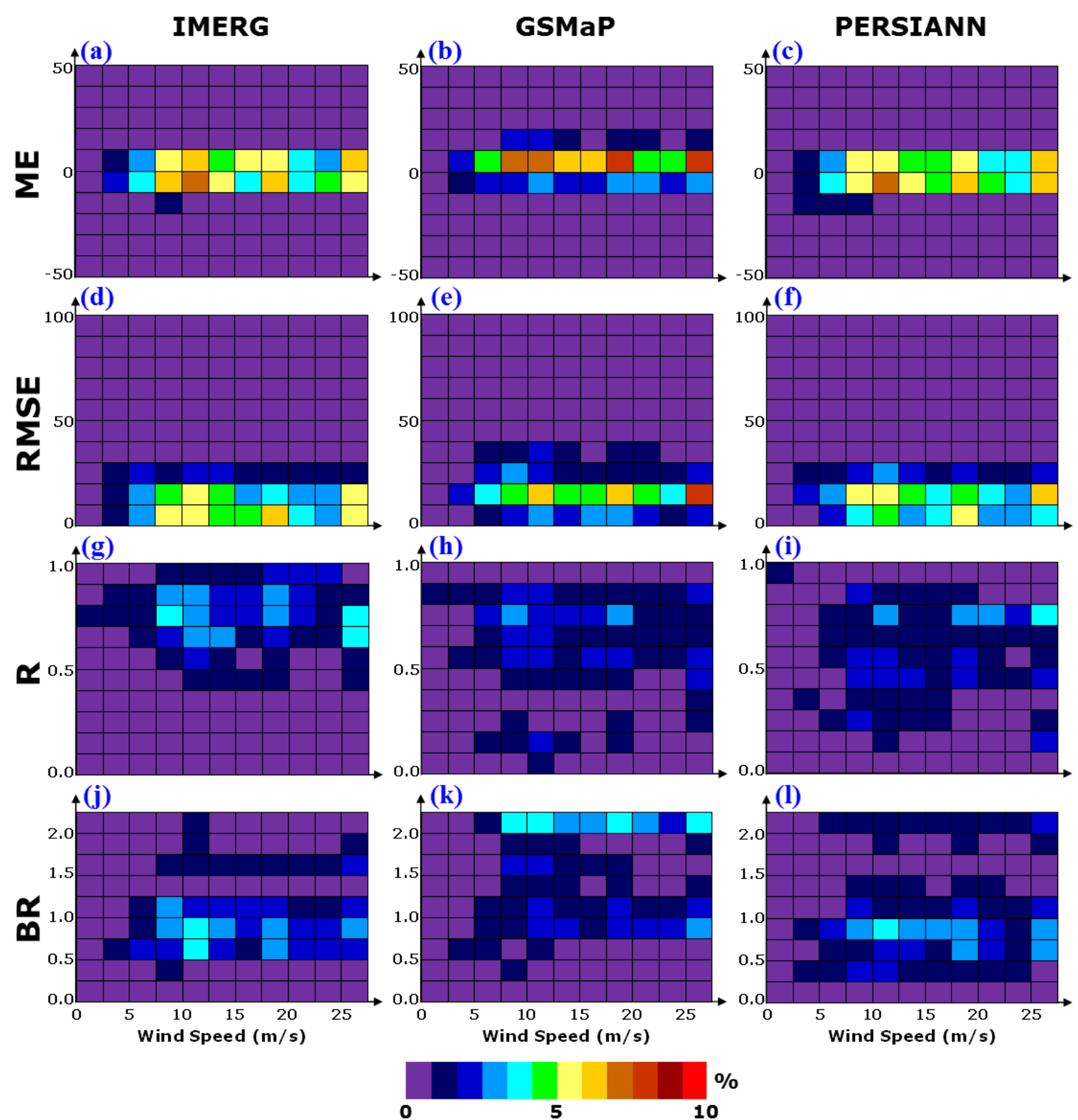

(l)

1061 Figure 6. Distribution percentage of each continuous statistic for the IMERG, GSMaP, 1062 and PERSIANN datasets at different wind speeds: (a-c) ME, (d-f) RMSE, ( $\mathrm{g}-\mathrm{i}) \mathrm{R}$, and 1063 (j-1) BR. The ME and RMSE value are presented in $\mathrm{mm} / 3$ hours. 

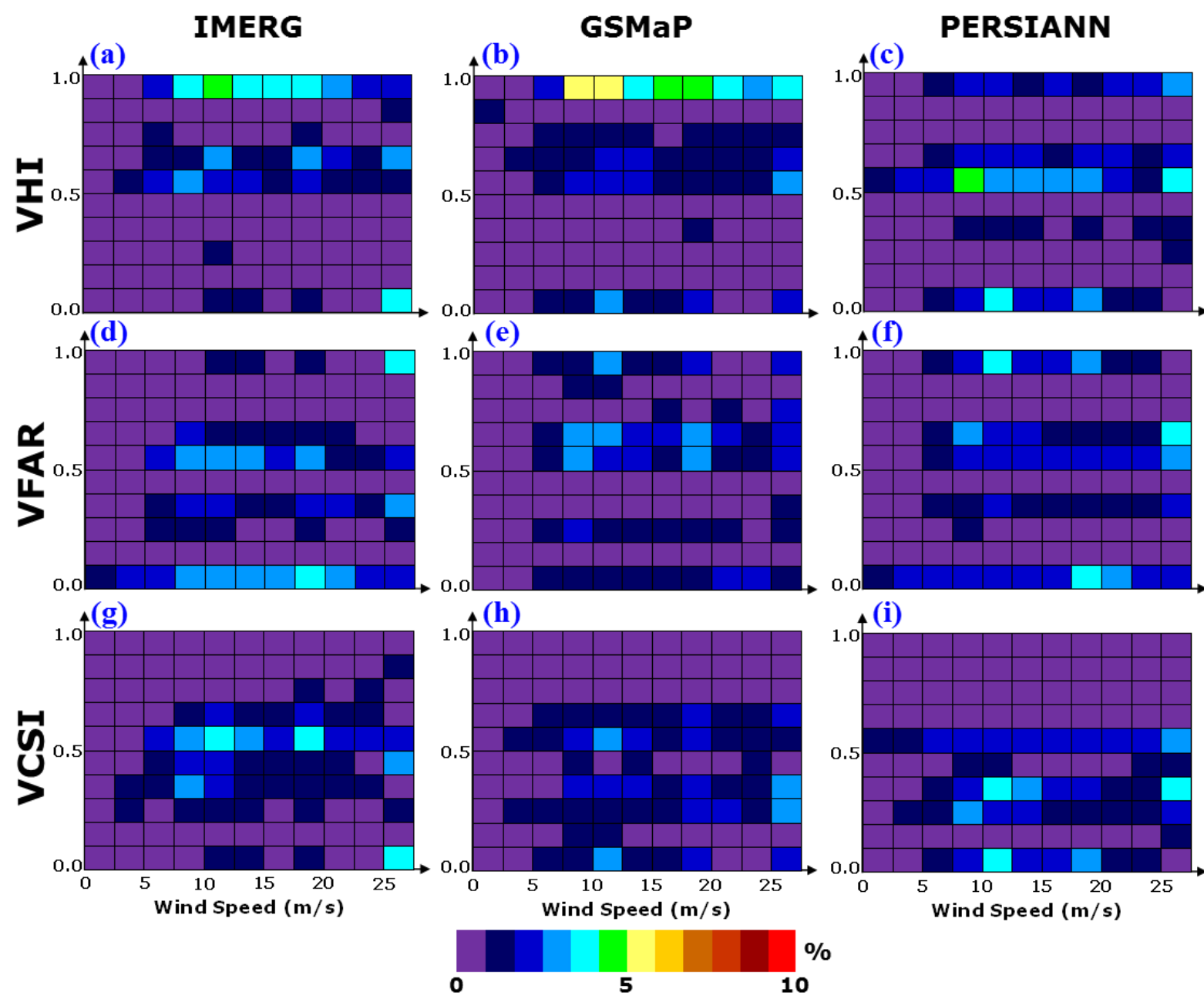

Figure 9. Distribution percentage of each volumetric index for the IMERG, GSMaP, 1067 and PERSIANN datasets at different wind speeds: (a-c) volumetric hit index (VHI), 1068 (d-f) volumetric false alarm ratio (VFAR), and ( $\mathrm{g}-\mathrm{i})$ volumetric critical success index 1069 (VCSI).

1070 

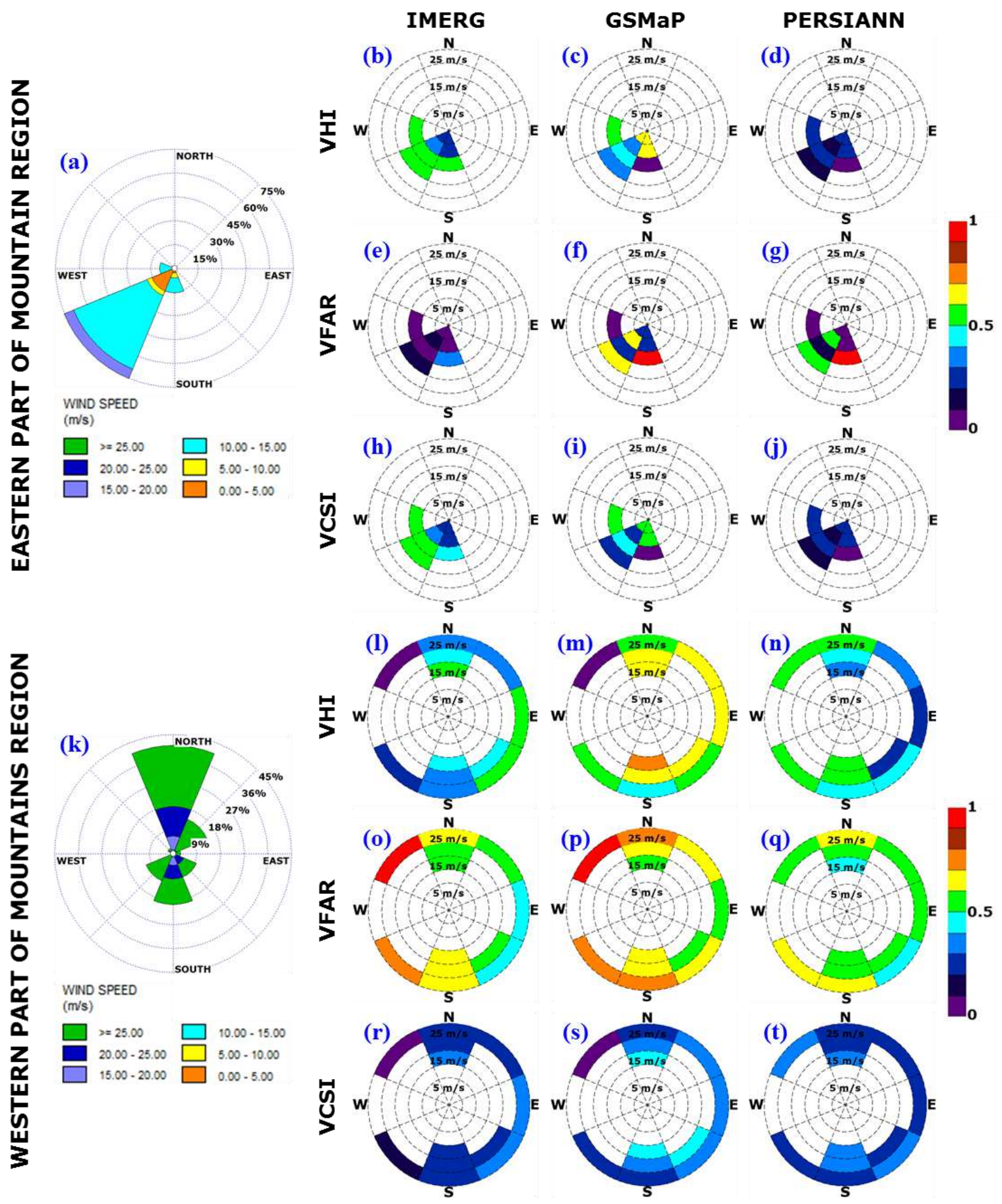

Figure 10. Three-hour, eight-sector wind rose and distribution of volumetric indices for

1073 the IMERG, GSMaP, and PERSIANN datasets for different wind directions and wind

1074 speed ranges on Luzon island: (a) wind rose for the eastern part of the mountainous

1075 region, (b-d) VHI for the eastern part of the mountainous region, (e-g) VFAR for the

1076 eastern part of the mountainous region, $(\mathrm{h}-\mathrm{j}) \mathrm{VHI}$ for the eastern part of the

1077 mountainous region, $(\mathrm{k})$ wind rose for the western part of the mountainous region, (1-

$1078 \mathrm{n})$ VHI for the western part of the mountainous region, $(\mathrm{o}-\mathrm{q})$ VFAR for the western part 
1079 of the mountainous region, and $(r-t)$ VHI for the western part of the mountainous region.

1080

1081 